
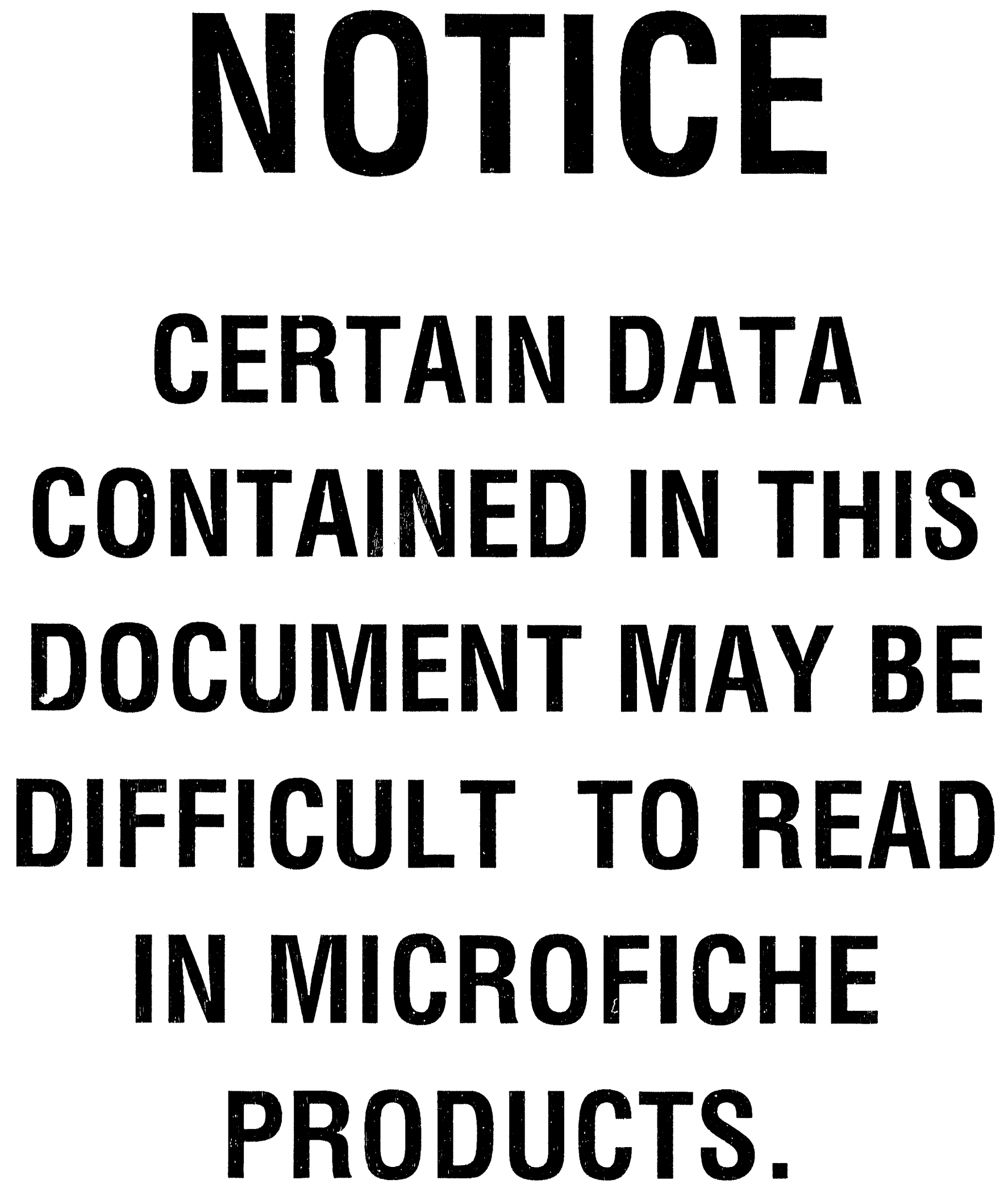


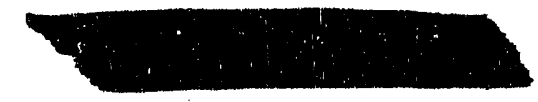

\title{
SEISMIC ANALYSIS OF REACTOR EXHAUST AIR FILTER COMPARTMENT(U)
}

\author{
CHUNG GONG, E. L. FUNDERBURK and JEFFREY W. JERRELL
}

September 1990
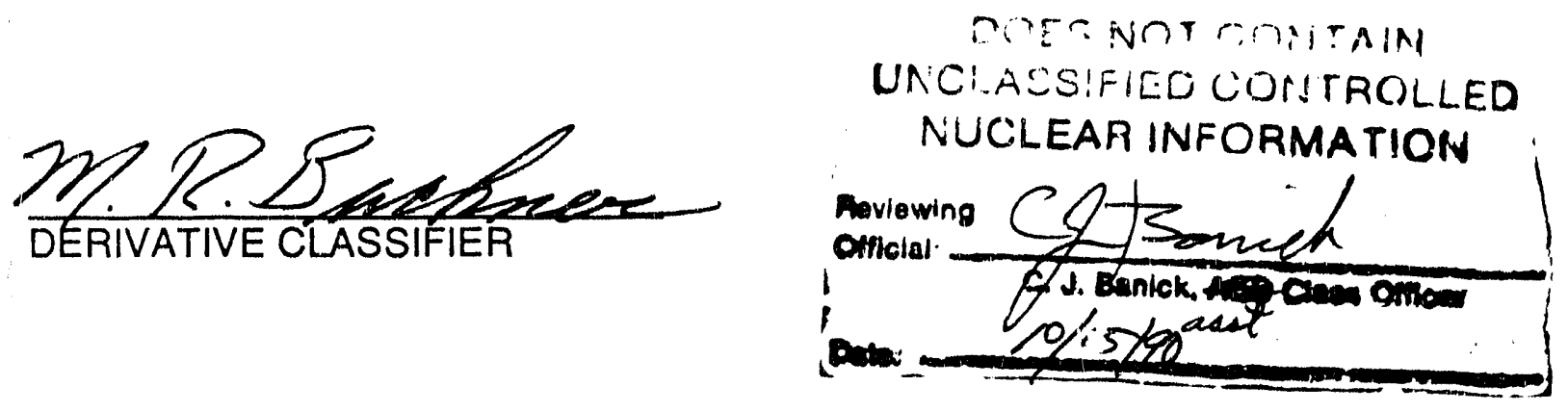

$$
\begin{array}{r}
\text { Westinghouse Savannah River Company } \\
\text { Savannah River Laboratory } \\
\text { Aiken, SC } 29808
\end{array}
$$

Prepared for the U. S. Department of Energy under Contract DE-AC09-88SR18035 
This report was prepared by Westinghouse Savannah River Company (WSRC) for the United States Department of Energy under Contract No. DE-AC0988SR 18035 and is an account of work performed under this contract. Neither the United States Department of Energy, nor WSRC, nor any of their employees makes any warranty, expressed or implied, or assumes any legal liability or responsibility for the accuracy, completeness, or usefulness, of any information, apparatus, or product or process disclosed herein or represents that its use will not infringe privately owned rights. Reference herein to any specific commercial product, process, or service by trademark, name, manufacturer or otherwise does not necessarily constitute or imply endorsement, recommendation, or favoring of same by WSRC or by the United States Government or any agency thereof. The views and opinions of the authors expressed herein do not necessarily state or reflect those of the United States Government or any agency thereof. 
NRTSC

Technology

On Time

On Target
WSRC-TR--90-406

DE92 015106

KEY WORDS: Reactor Restart

Airborne Activity Confinement

System

Frequency Analysis

Finite Element Analysis

Structural Dynamics

Response Spectrum Analysis

Reactor Filter Structural Analysis

Earthquake Engineering

Linear Elastic Stress Analysis

RETENTION PERIOD: LIFETIME

\section{SEISMIC ANALYSIS OF REACTOR EXHAUST AIR FILTER COMPARTMENT(U)}

By

CHUNG GONG, E. L. FUNDERBURK and JEFFREY W. JERRELL

ISSUED: September 24, 1990

\section{SRL}

SAVANNAH RIVER LABORATORY, AIKEN, SC, 29808

Westinghouse Savannah River Company

Prepared for the U. S. Department of Energy under Contract DE-ACC9-88SR18035 


\section{DOCUMENT: WSRC-TR-90-406}

TITLE: SEISMIC ANALYSIS OF REACTOR EXHAUST AIR FILTER COMPARTMENT(U)

\section{APPROVALS}

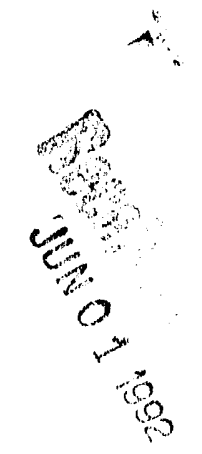

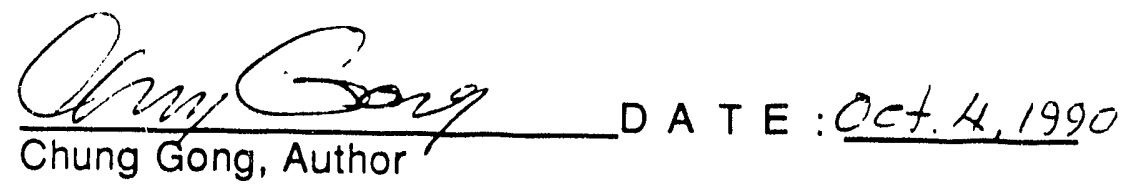

E. L. Fundirburk, Author

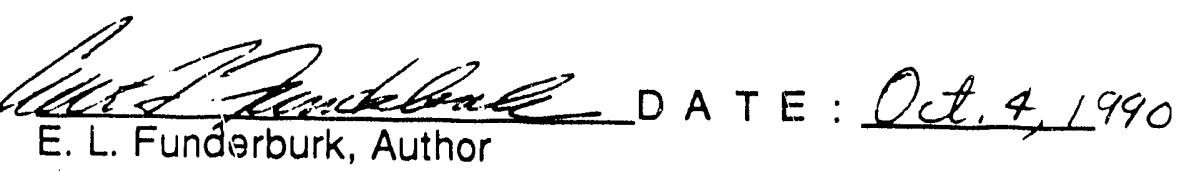

Wefhen zi: Desself D A T E : Oet 4,1990

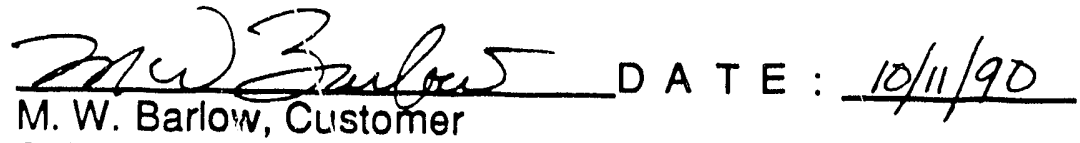

Seismic Engineering

$\frac{\text { SRyeyrey }}{\text { J. B. Pelfrey.Manatger D T E : } 10-4-90}$

Computational Modeling and Applied Statistics Group

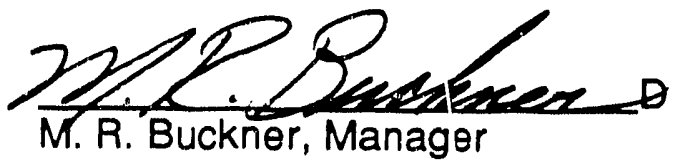

A TE: $10-4-90$

Scientific Computations Section 


\section{CONTENTS}

1. INTRODUCTION AND SUMMARY ...................................

1.1 SUMMARY Y.....................................................2

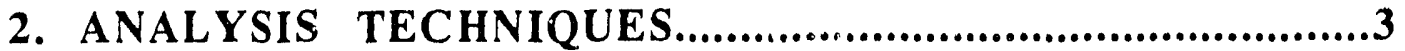

2.1 Data Available.................................................3

2.1.1 Geometric Configuration and Mechanical Properties of Structural Members.....................3

2.1.2 Materials..........................................................3

2.1.3 Applied Load..................................................3

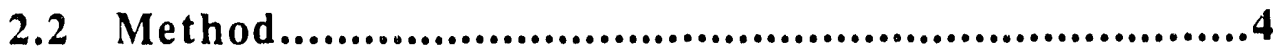

2.2.1 Computer Code......................................................4

2.2.2 Modeling.......................................................4

2.2.2.1 Material ( mechanical ) Properties.................5

2.2.2.2 Finite Element Discretization.........................6

2.2.2.3 Boundary Conditions.......................................7

2.2.2.4 Model Combination..........................................7

2.2.2.5 Floor Response Spectra.................................8

2.3 Computer Dynamic Modal Response Spectrum Analy sis............................................................9

2.3.1 Test Runs......................................................9

2.3.2 Dynamic Analysis of Full Model with MPC's...9

2.3.2.1 Model with Partially supported Plenum Plate.......................................................................9

2.3.2.2 Model with Stress Output Points in Beams..9

2.3.2.3 Model without Partially Supported Plenum Plate and 26 Eigenmodes included..................10

2.3.3 Static Analysis ( Gravitation )........................12 
3. CONCLUSION AND SUGGESTIONS....................................12

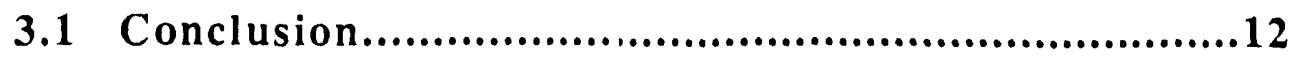

3.2 Suggestions..................................................17

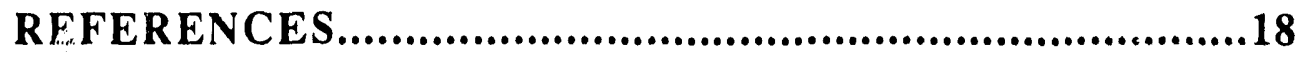

ACKNOWLEDGEMENT............................................20

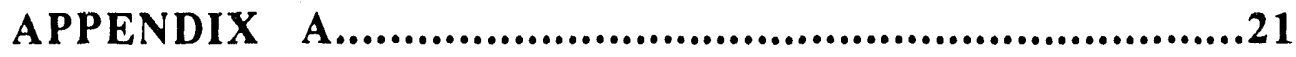

APPENDIX B.....................................................23

\section{FIGURES}

TABLES 


\section{INTRODUCTION AND SUMMARY}

The Filter Compartment (FC) in this analysis is a generic reactor airborne activity confinement filter compartment which possesses all the essential physical and mechanical properties of the $\mathbf{S}$ avannah River Site (SRS) confinement filters of Reactor Buildings $K, L$, and $P$. The filters belong to the A irborne Activity Confinement System (AACS). These filters absorb a significant amount of radioactive effluents from the exhausting air.

This generic FC is located on the roof of the 105 Exhaust Stack building at the elevation of 55 feet. The center of the top nozzle is at 75 feet. The exterior of the FC resembles the appearance of a "trailer" ( see Figure 1) with measurement: 21 feet 9 inches in length, 8 feet 10 inches in width and 21 feet 6 inches tall. Inside the $\mathrm{FC}$, at the upper part of the compartment, there is a plenum which guides the exhausting air flow from the top (inlet) nozzle. Underneath the plenum there are three upright filter racks (for the Carbon, HEPA, and Demister filters respectively) ( see Figure 3 ).

The whole FC structure is made of aluminum alloys. The frame and racks are mostly composed of beams and columns with $\mathbf{I}, \mathbf{T}, \mathbf{L}$, and rectangular sections and the composition of two or more of these sections which are made of 6061-T6 alloys. The skins of all the six faces of the FC are made of curved shells. The plenum is constructed with both flat plates and curved shells. The nozzles are large cylindrical shells with a radius of 28.625 inches. The shells and plates are made of 3003-H112 ( and H16) aluminum alloys.

The base of the FC is in contact with the rail-dolly en the building roof. The two nozzles are loosely connected to the exhaust pipes from the building wall through neoprene gaskets such that sliding motion along the cylindrical interfaces is not restricted.

The seismic excitation is input indirectly from the output of the seismic analysis of the 105 exhaust stack building in the form of floor response spectra. However, the 105 exhaust stack building was analyzed for seismic motions defined by free-field ground response spectra with a ZPA ( Zero Period Acceleration) of $0.2 \mathrm{G}$ for all three crthogonal components of ground motion and a shape consistent with USNRC Regulatory Guide 1.60 . 
Based upon equivalent dynamic analysis of the FC, DuPont engineers suggested modifications on the existing FC with heavy I-section beams [1].

The scope of this "phase I" analysis, as requested by Seismic Engineering [2], is to carry out a "scoping analysis" of Frequency Analysis and Response Spectrum Analysis of the FC with DuPont suggested conceptual modifications.

Our suggestion was that the existing FC without conceptual modifications be analyzed first. However, the schedule urgency of the project and with guidance from the previous seismic analysis established the priority to perform the analysis for the FC with modifications in the "phase I" calculation.

\subsection{SUMMARY}

A general purpose Finite Element Analysis program, ABAQUS, is used to perform the Modal Response Spectrum Analysis of the FC. The heavy stiffeners suggested by the modifications and the vertically fixed base boundary conditions make the FC considerably stiff. Consequently, the fundamental frequency of the FC reaches 14.925 Hertz, which is higher than what was expected. The effective mass for the vertical vibration modes is only $3 \%$ of that for the horizontal modes. At this frequency $(14.925$ Hertz) the effective vertical spectral acceleration is reduced to $1.29 \mathrm{G}$ and the effective horizontal spectral acceleration diminishes to $0.75 \mathrm{G}$. With these low spectral accelerations, both the displacement and stress responses of the FC are accordingly small.

Since the effective mass of the vertical component is so low, it is justified to carry out the equivalent static analysis for the spect 1 loading beyond the cut-off frequency, viz., $33.0 \mathrm{Hertz}$. The ZPA of the vertical spectrum at $33.0 \mathrm{Hertz}$ is $0.81 \mathrm{G}$. With the reduction factor 0.6667 specified in this calculation, the actual ZPA becomes $0.54 \mathrm{G}$. The static dead weight responses were computed with $1.0 \mathrm{G}$ vertical gravitation load. Therefore the corresponding dynarnic responses to the $0.54 \mathrm{G} \mathrm{ZPA}$ can be obtained by multiplying the static responses by the factor 0.54 . Adding $54 \%$ of the vertical static responses to the dynamic responses, we find that the maximum Von Mises stress in shells is $2,140.5$ psi. The maximum beam stresses are $3,356.7 \mathrm{psi}$ for axial and 4,222.7 psi for shear. These stresses are well below the minimum yield strength of the aluminum alloys used 
in this FC. The maximum horizontal displacement is less than 0.12 inches in the direction along the nozzle axis and the maximum vertical displacement is also a midget 0.13 inches.

Without fastening devices, the dead weight of the FC is insufficient to hold the compartment down to the building roof during a seismic event with $0.2 \mathrm{G} \mathrm{ZPA}$.

The conceptual modifications and the boundary conditions certainly shield the FC well from earthquakes. It is also important to have a better understanding of the real vulnerability and survivability of the FC during a seismic event. Hence a thorough seismic analysis of the "as is" existing FC is recommended.

\section{ANALYSIS TECHNIQUES}

\subsection{Data Available}

\subsubsection{Geometric Configuration and Mechanical Properties of Structural Members}

The geometric configuration and dimensions are obtained from the shop drawings: BPF 211147 drawing numbers FD.405-001 to 026 [3]. The Mechanical Properties of various structural members are computed from the shapes and materials indicated in the drawings.

\subsubsection{Materials}

Two Aluminum alloys are used in construction of this FC. In general the alloy 3003- H112 ( $\mathrm{H} 16$ for plenum) is for plate and shell members, while the alloy 6061-T6 is used for beams and columns [3].

\subsubsection{Applied Load}

Seismic Engineering provided [4] the "Preliminary amplified floor response spectra for AACS filter compartments on $\mathrm{K}, \mathrm{L}$, and $\mathrm{P}, 105$ exhaust sta',k buildings" with $3 \%$ damping, as the seismic loading for the response spectrum analysis. These spectra are shown in Figures 4-6.

1. Vertical smoothed floor response spectrum, Figure 4.

2. East-West smoothed floor response spectium, Figure 5.

3. North-South smoothed floor response spectrum, Figure 6. 


\subsection{Method}

The FC consists of compartment walls, which are built with curved shells, two nozzles, a plenum, three filter racks, and the floor and roof, both covered with curved shells. The dynamic linear modal seismic response spectrum method was adopted as the practical and expedient scoping analysis method. The actual boundary conditions include gaps and contact surfaces. In using this method, the complicated geometric and structural configurations, as well as the nonlinearities, necessitated linearization of the boundary conditions and certain modeling simplifications. Nevertheless, the objective is to insure that the FC will sustain only elastic deformation, during seismic excitations. After the earthquake the FC elastic deformations must be recovered and thus the FC will be functioning immediately after the shock without any by-pass of effluents. Therefore, linear elastic analysis is the appropriate method to be applied in this case.

\subsubsection{Computer Code}

ABAQUS is a general purpose Finite Element Analysis program which can perform both Static and Dynamic analyses of linear as well as nonlinear problems. The theoretical manual indicates that this code uses the state-of-the-art approaches in the numerical analysis that is essential for the reliability and accuracy of the calculations. ABAQUS also provides the response spectrum analysis procedure. ABAQUS is installed on the SRS CRAY XMP computer.

\subsubsection{Modeling}

Both geometric and mechanical properties modeling of the FC are carried out with PATRAN, a pre- and post-processing code.

Phase I of PATRAN modeling sets up the grid of the physical geometric configuration. In this Phase the grid network of lines and patches is constructed according to the geometric configuration of the FC. In this grid network each line and patch passes through the material centroids of the structural members. In phase II of PATRAN modeling the physical beams, plates and shells are mapped onto the grid network as finite elements. In order to include the curvature of the shells in the model, the size of the elaments is drastically reduced, since, according to the ABAQUS muitual, the surface normals between adjacent curved shell elements must be within 15 degrees apart for smooth connectivity.

Figure 2 shows the overall element mesh of the FC. The curved shells are rather composed of flat plates, such that at the edge of the 
intersection of two adjacent elements there are two distinct normals. However, the angle between these two normals is less than 15 degrees. In $A B A Q U S$ a unique normal which is equal to the average of the two normals will be chosen along the edge. The element between edges will be modelled as a curved shell element. The unique normal along the intersection edge of adjacent elements provides continuity of curvature. Figure 3, with the side wall shell elements deleted, shows the inside modeling of the FC. This Figure reveals the curved shell elements on all the six faces of the FC. The plenum, and one ( the carbon filter rack) of the three filter racks are meshed with plate elements. Except for two rows of plate elements at top and bottom of the Demister filter rack all the filter racks are modelled with beam elements.

Only a limited number of beam cross-sections with simple geometric configurations are available in the ABAQUS code. Therefore all the sectional properties of beams with simple as well as composite cross sections are manually computed [6] (see Table 1). The complicated beam cross section configurations make it difficult to precisely calculate beam stresses. A list of section points for all the beams in this model is conservatively estimated based upon best engineering judgements. This list of section points is part of the ABAQUS input data.

\subsubsection{Material ( mechanical ) Properties}

Two aluminum alloys are used in this FC construction, viz., 3003H112 ( H16), and 6061-T6. According to the " ALCOA Structural Handbook " by Aluminum Company of America, 1960, Tables 3a, 4a, and $4 \mathrm{~b}$ :

Alloys

Weight $\left(\mathrm{lb} /\right.$ in $\left.^{3}\right)$

Young's Modulus(ksi)

Shear Modulus(ksi)

Poisson's Ratio

Yield Strength(ksi)(T)

Yield Strength(ksi)(C)

Yield Strength $(\mathrm{ksi})(\mathrm{S})$

Yield Strength(ksi)(B)
$6061 \cdot \mathrm{T} 6$

0.098

10,000

3,750

0.3333

35

35

20

56
$3003 \cdot H 112$

0.099

10,000

3,750

0.3333

10

9

6

17
$3003-H 16$

0.099

10,000

3,750

0.3333

12

33

where (T), (C), (S), and (B) denote Tension, Compression, Shear, and Bearing respectively. 
Weight of Filter Compartment Components [4]

Component Source of Information Weight(lbs)

Carbon cell Vendors QA Report 140

Particulate filter Shipping Weight 50

Demister cell Call to vendor $\quad 11$

32 Carión cells 4480

32 Particulate filters 1600

24 Demister cells 264

Weight of FC (including filters) Analysis 21155

Equivalent Carbon Cell Plates ( on both faces of the Rack ):

$\begin{aligned} \quad \text { Thickness } & =0.3 \text { inches } \\ \text { Weight } & =0.405 \mathrm{lbs} / \mathrm{in}^{3} \\ \text { Young's Modulus } & =7,250 \mathrm{ksi} \\ \text { Shear Modulus } & =2,788.46 \mathrm{ksi} \\ \text { Poisson's Ratio } & =0.30\end{aligned}$

Material Damping for all components and members is conservatively estimated as $3 \%$ of critical damping.

\subsubsection{Finite Element Discretization}

There are two important criteria for the discretization of this finite element model, viz.,

1. There must be a sufficient number of elements to describe the geometric configuration and the connectivity of the FC structure.

2. At the highest mode of this analysis (i.e. at frequency $=33$ Hertz ), there must be about ten elements in each of the wave lengths, such that the error in the analysis will be kept below 5\% from the analytic solution. ( Ref. " Dispersion and Anisctropy Induced in Finite Element Analysis ", by Chung Gong , 1974 ). Note that the wave lengths in beam and shell members are calculated in accordance with the respective theories ( e.g., Timoshenko beam theory, Mindlin plate and beam theories).

According to these two criteria, the FC struciure was discretized into approximately 10,000 nodal points and about same number of beam and shell elements. Mathematically, in this model, a beam is described by a line and a shell element is a sheet without volume. 
All the lines representing beams and columns and the 2-D manifolds as shells are geometrically located at the centroids of the real physical structural members whicil in actuality are three dimensional solid elements. The voids left by the mathematical modeling are filled either by rigid members or through Multi-Point Constraints ( MlC ). Particularly, the curved shell skins of the six faces of the FC are welded to the beams and columns. The curved shells and the beam or column elements are connected with MPC's. For smoothness of the connectivity between adjacent curved shell elements, the arc angular length of each element is maintained less than 15 degrees.

The beam elements used in ABAQUS are type B31 which is a 2-node beam with linear interpolation. Two doubly curved shell elements used in this model from the ABAQUS element library are Quadrilateral shell element S4R5 and Triangular shell element STRI35.

\subsubsection{Boundary Conditions}

For each of the two nozzles at the nozzle-pipe interface, the translational displacement along the nozzle axis and the rotation about the nozzle axis are discontinuous. The rest of the degrees of freedom at this interface are to be modeled as if the nozzle-pipe interface is continuous. The restraint due to the latch between the two nozzles, the upper guide and the dog legs or lower guides is conservatively not included. At the interface between the FC base and the rail-dolly, the horizontal displacement along and perpendicular to the rail at each of the two guide cones is set to zero. All other contact points at the base of the FC were set to have no vertical movements $[2,4]$. This decision was guided by the previous information and judgement that the weak and flexible rail-dolly, if included in the model, will further amplify the FC response, and in turn will reduce the possibility of showing adequacy of the FC.

\subsubsection{Modal Combination}

The subspace iteration technique is applied to extract the natural frequencies and the corresponding characteristic mode shapes of the FC structure. For the purpose of efficiency and obtaining answers with reasonable engineering accuracy the number of eigenpairs requested is set to 30 , the highest frequency of interest is $33.0 \mathrm{Hertz}$, the maximum number of iterations allowed is 20 , the number of vectors used to define the subspace is 60 , and the default tolerance is used ( i.e., 1.0E-05). 
The modal responses for all modes below 33 Hertz shall be combined according to the Square R oot of Sum of Squares ( SRSS ) method [5].

The effect of higher modes with frequencies greater than or equal to 33 Hertz shall be computed and accounted for using the Zero-PeriodAcceleration (ZPA) method which uses the ZPA to perform static analysis in each directiori of seismic shock. The ZPA is the spectral acceleration at 33 Hertz unless a different frequency is justified.

The resultant response of all the lower modes below 33 Hertz shall be combined with the resultant response of all the higher modes using the SRSS procedure.

The three components of earthquake shock (two horizontal and the vertical) shall be considered to act simultaneously. The seismic response for each individual unidirectional shock shall be combined by the SRSS procedure to obtain the response due to three components acting simultaneously [2,5].

\subsubsection{Floor Response Spectra}

The floor response spectra for East-West Horizontal, North-South Horiz, 1 , and Vertical accelerations ( in terms of gravitation $G$ ) are gi: a in graphic form [4] ( see Figures 4-6). These spectra are carefully digitized ( Table 2 ) and reproduced in graphic form for comparison ( see Figures 7-10). The input acceleration in the building analysis, which generated the floor response spectra, was a $0.2 \mathrm{G}$ ZPA (Zero-Period-Acceleration) USNRC Regulatory Guide 1.60 Ground Spectra with an amplification factor of 2.0. This amplification factor of 2.0 was used to provide a margin for an increase of ground response spectra to a $0.3 \mathrm{G} \mathrm{ZPA}$, and to provide a seismic motion input at higher elevation ( El. 66' ) on the inlet and outlet nozzles as well as to allow for the differences in the three reactors' analyses. Because of the different orientation in the $L$ and $P$ Reactors, the two Horizontal spectra are numerically enveloped, i.e., in the response spectra analysis the two horizontal spectral components will use the same enveloped spectrum. To obtain the floor response spectra corresponding to the $0.2 \mathrm{G}$ ZPA ground response spectra ( in the building analysis ), a reduction factor of $0.6667(2 / 3)$ is applied to all the three components of the floor response spectra for this analysis. 


\subsection{Computer Dynamic Modal Response Spectrum Analysis}

\subsubsection{Test Runs}

Several test runs were performed to check the capacity of the computer as well as the program ABAQUS. Detailed testing experiences are discussed in the Appendix A.

\subsubsection{Dynamic Analysis of Full Model with MPC's}

2.3.2.1 With the necessary MPC's implemented in the full model, the frequency analysis of this model indicated an increase in frequency as expected. The cut-off frequency is $33.0 \mathrm{Hertz}$. The Response Spectrum Analysis is performed up to 20 eigenmodes which includes the 33.0 Hertz mode. Again the results indicate that the maximum Von Mises stress in shell elements is still within $5.0 \mathrm{ksi}$. If ABAQUS could provide data combination ( for stresses in elements and displacements and reaction forces at nodal points ) from various output files, then the result would be combined ( absolutely adding) with the Static Analysis. The Static analysis would use the same numerical model with static gravitational loads. The gravitational loads would be computed from the Spectral data at the cut-off frequency ( i.e., 33.0 Hertz ).

However, for the time being ABAQUS does not have the capability to do the combination and the tight schedule does not permit an inhouse development of a post processing program. An alternative strategy is applied to solve this problem.

2.3.2.2 The calculation in 2.3.2.1 was repeated with additional input data. Various composite sections ( besides simple sections) of beams ( and columns) are used in this model, as it is almost impossible to compute the beam stresses precisely. The beam geometrical properties have been manually calculated [6]. In this run we also ( based upon our best conservative engineering judgement ) insert a list of the section points ( see Table 3 ) for each beam section, at which beam stresses are recorded. The maximum beam axial stress in this calculation is $2,726 \mathrm{psi}$, and is in the floor of the FC.

2.3.2.3 By inspection of the frequency spectrum of the previous caiculation we decided to include the first 26 [7] modes in the Response Spectrum Analysis. A few improvements are incorporated in this new model. 
First, the interface between the exhaust pipe beam and the nozzle shell is connected through a couple of equations. In each of the equations, the motion of a node on the beam was made equal to the average motion ( in the $\mathrm{Y}-\mathrm{Z}$ plane) of eight nodal points on the nozzle shell in the same plane (includes the beam node). These equations provide continuity between the nozzle shell and the exhaust pipe beam. In the meantime, the beam can freely move (relative to the nozzle shell longitudinally and rotationally) in the axial direction.

Second, as we observed in the previous runs, the partially supported plenum flat plate absorbs most of the energy in the symmetric modes. The partially supported plate shows excessively large deflection ( 1.305 inches ) and high stress concentration ( $4778.0 \mathrm{psi}$ Von Mises stress ) which are not necessarily realistic. In this model, we removed the partially supported flat plate in the plenum. Due to the removal of the flat plate, the fundamental frequency of the FC system moved up from 5.0929 Hertz to 14.925 Hertz. The frequency outputs from these two caiculations are shown in Tables 6 and 7 respectively.

By including the first 26 modes in the Response Spectrum Analysis, this model contains a spectral frequency up to 41.579 Hertz which, according to the effective mass calculation, indicates that the system has at least $99 \%$ of the total effective mass participated in the response. The maximum Von Mises stress in shells reduced to 1453.0 psi ( element number 351 which is at the top nozzle wall). The maximum axial stress in the floor beam increases a little to 2,739 psi.

In spite of the slight increase in maximum beam stress, the Von Mises stresses in shells in both runs ( the models with and without the partially supported plenum flat plate) are very close to each other, except, of course, for the partially supported flat plate. Further examination of the Von Mises stress contours indicates that in the previous model all the high stresses in the shell elements are concentrated in the partially supported flat plate (plenum). it corfirms that the new model calculation is at least as reliable as the previous one.

Figure 11 is a contour plot of Von Mises stress in shell elements in the whole structure. It indicates stress concentration in the nozzle shell elements. Figure 12, with the side wall shell elements removed, shows the stress concentration on the bottom of the FC at the location 
of the guide cones. Figure 13 shows a blowup in the stress concentration area of the upper nozzle wall.

For the beam elements, ABAQUS provides both sectional forces, moments, and sectional stresses. However, the stress calculation in ABAQUS is incorrect for the Response Spectrum Analysis. The sectional stresses for the beam elements are recalculated as follows:

1. For each type of beam, find the maximum sectional force comfonent with respect to all the beams in this type. That is, the collection of all the six components of maximum sectional forces may not occur in any particular beam element, but certainly the collection will envelope all the maximum forces in this type of beam.

2. Divide axial force and the shear forces by the sectional area to obtain the axial stress and shear stresses, respectively, in the beam section.

3. Based on engineering judgement, the location of maximum stress in the beam section is determined by giving the local coordinates $\mathbf{x}$, $y$ with respect to the centroid of the section.

4. Defining $\mathbf{r}=\operatorname{SQRT}\left(\mathbf{x}^{2}+\mathbf{y}^{2}\right)$, torsional stress is theil computed by taking torque times $\mathbf{r}$ and dividing by the torsional stiffness of the beam.

5. Add the torsional stress to the square root of the sum of squares of the shear stresses ( in step 2 ) to obtain the combined shear stress.

6. Use conventional theory to compute the bending stresses in each direction ( $\mathbf{x}, \mathbf{y}$ are used properly )

7. Add the axial stress to the two bending stresses to obtain the combined axial stress.

8. Assuming minimum axial stress to be zero, the combined axial and shear stresses provide principal stress and maximum shear stress in the beam.

9. The calculation procedure as well as the final results for all types of beams used in this model are shown in Table 4 . 
The maximum principal stress in the beams is $2.74 \mathrm{ksi}$, and maximum shear is $2 \mathrm{ksi}$, both well below the yield strength.

\subsubsection{Static Analysis ( Gravitation)}

For the purpose of evaluating the reasonableness of the boundary conditions between the base of the FC and the rail-dolly, i.e., zero vertical deflection, and for computing static response of the FC, the stress distribution due to dead weight is computed in this Static Analysis. The maximum Von Mises stress in the plenum shell element 6107 is 446.4 psi. The maximum shear stress in the upper side wall - horizontal I-beam (element 3484) with nodes 4676 and 4727 beams is $1468.0 \mathrm{psi}$. The maximum axial stress in a plenum beam (element 2198) with nodes 875 and 876 is 401.4 psi.

\section{CONCLUSION AND SUGGESTIONS}

\subsection{Conclusion}

The Finite Element Model of the Filter Compartment provides detailed simulation of the essential parts of the structure. Sophisticated modeling techniques are demonstrated in the modeling of curved shells, nozzle ribs, the connections between beams and columns and shells through MPC's and the partial continuity between the nozzle shells and the exhaust pipes which were modelled with beam elements. All these meticulous efforts are necessary for the integrity and preciseness of the numerical model. The first frequency, $14.925 \mathrm{Hertz}$, of the FC without the partially supported plenum plate is the consequence of the Boundary Conditions. The complete constraining of the FC base in the vertical direction and the connectivity between the nozzle walls and the exhaust pipes from the building wall make the vertical symmetrical modes as rigid body motions.

1. Overall the stresses in both the shells and beams are low.

* Maximum Von Mises stress in shells:

Dynamic with 26 modes: $1,453.0$ psi

Static with dead weight: $446.4 \mathrm{psi}$

Total

$1,899.4 \mathrm{psi}$ 
* Maximum Shear stress in beams:

Dynamic with 26 modes: $1,962.0 \mathrm{psi}$

Static with dead weight: $1,468.0 \mathrm{psi}$ Total $\quad 3,430.0 \mathrm{psi}$

* Maximum principal stress in be'ams

Dynamic with 26 modes: $2,738.5 \mathrm{psi}$

Static with dead weight: $\quad 401.4$ psi

Total

$3,139.9 \mathrm{psi}$

These stresses are well below the limiting stress i.e., $90 \%$ of the yield stress. The lowest shear strength is $90 \%$ of $6,000 \mathrm{psi}$, or $5,400 \mathrm{psi}$.

Note that the Von Mises stress in the partially supported plenum flat plate is also less than 5,000 psi.

The fundamental frequency of this model is 14.925 Hertz which is beyond the frequencies where peak accelerations occur in the floor response spectra. The peak of the vertical spectrum is maintained at $5.35 \mathrm{G}$ within the frequency range from 8.4 to $12.4 \mathrm{Hertz}$. The peak of the enveloped horizontal floor response spectrum has a value of $6.4 \mathrm{G}$ within the frequency range from 3.8 to $6.0 \mathrm{Hertz}$. The vertical component with a wide peak range could cause a tremendous impact upon the FC. However, the vertical motion of the FC is severely restricted by the boundary conditions. The effective mass of the vertical component in the frequency analysis is only about $3 \%$ of that of the horizontal components. Therefore the influence of the vertical floor response spectrum to the FC is considerably diminished.

The horizontal modes certainly dominate the seismic activity of the FC, yet for frequencies beyond 12.8 Hertz the enveloped horizontal floor response spectrum shows the acceleration of $1.13 \mathrm{G}$ which is only $17.7 \%$ of the peak value, $6.4 \mathrm{G}$.

The low stress level in this calculation as compared with the previous analysis (even though these are completely two different approaches, this one is dynamic while the previous calculation was static ) is mainly due to different loading and boundary conditions.

2. Based upon the mass density used in this anaiysis, the total weight of the FC is 21,155 pounds. At the base of the FC there are 215 nodal points which are vertically constrained to the rail-dolly. Eight nodes, 
as the guide cones, are also constrained in horizontal directions to the rail-dolly.

The pressure distribution over the base cannot be uniform. Listed here is the vertical pressure distribution over the 215 nodes on the FC base ( see Table 5 ). Table 5 lists, for every base node, the maximum reaction force during a seismic event, the reaction force from the dead weight, and the difference between the two reactions. For clarity, the difference of the reactions is also separated into two columns, the positive force implies uplifting, whereas the negative force implies down-holding. The total dead weight is 22,565 pounds which is slightly heavier than the weight calculated from mass, probably due to numerical inaccuracy ( about $6.7 \%$ ).

Without special devices to fasten the base of the FC to the rail-dolly and the rail-dolly to the roof of the building, as assumed in this analysis, the FC will certainly have uplift during the seismic events. In Table 5, it shows that among the 215 base nodes, 81 nodes have down-holding dead weight reaction forces larger than the the dynamic uplifting forces, specially at those nodes in the vicinity of the carbon filter rack, where the dead weight reaction forces are much stronger than the dynamic forces. Nevertheless, the 113 base nodes with uplifting reaction forces will be detached from the raildolly if fastening devices are not provided at those nodes. At the moment a node is detached from the rail-dolly, the reaction force at that node is reduced to zero and the dynamic force at that node will be redistributed to other nodes which still have down-holding reaction forces over the dynamic forces. This reaction force redistribution process will continue over all the 215 base nodes. If the total dead weight were heavier than the total dynamic forces, there would be no uplifting or overturning for the FC. However, the total dead weight of the FC is only $22,565 \mathrm{lbs}$, whereas the total dynamic force is about 35,642 lbs. Because of the uneven distribution of the reaction forces, the total uplifting forces $(17,482$ lbs) is almost four times that of the down-holding forces $(4,405 \mathrm{lbs})$. This explains why the FC will be tossed by the seismic events.

3. Maximum Dynamic Displacements

$$
\begin{array}{lll}
D x=0.1137 \text { inches } & \text { Node } 2233 & \text { the plenum } \\
D y=0.0773 \text { inches } & \text { Node } 2051 & \text { middle of roof } \\
D z=0.0374 \text { inches } & \text { Node } 5174 & \text { mid of sidewall }
\end{array}
$$


4. Maximum Dead Weight Displacements

$$
\begin{array}{lll}
D x=0.0451 \text { inches } & \text { Node 2051 } & \text { middle of roof } \\
D y=0.0971 \text { inches } & \text { Node } 2051 & \text { middle of roof } \\
D z=0.0017 \text { inches } & \text { Node } 662 & \text { top of side wall }
\end{array}
$$

It is interesting to observe that the maximum vertical displacement (Dy) from the dynamic analysis (0.0773 in.) is smaller than that from the static analysis $(0.0971$ in.). Apparently, the high vertical spectral acceleration $(5.35 \mathrm{G})$ has little effect upon the FC. In the frequency analysis, it indicates that the vertical component of the motion has only $2 \%$ of the total vertical effective mass ( 1.5 mass unit which is approximately $3 \%$ of the horizontal component) in the first mode $(14.925 \mathrm{Hertz})$. At this frequency the vertical spectral acceleration is $1.94 \mathrm{G}$. The next significant contribution is from the sixth mode with frequency $25.114 \mathrm{Hertz}$, at which the vertical spectral acceleration is only $0.93 \mathrm{G}$. Assuming the contribution from the sixth mode and the rest of the higher modes is $98 \%$, then the total vertical spectral acceleration will be: $0.02 * 1.94+0.98 * 0.93=0.9502 \mathrm{G}$. In this analysis a reduction factor (0.6667) was applied. Consequently, the total effective vertical spectral acceleration is about $0.6335 \mathrm{G}$ which is only $63 \%$ of the gravitation ( while the calculation shows that the vertical dynamic displacement is about $80 \%$ of the static. Apparently the rest $17 \%$ of the vertical dynamic displacement is contributed by the horizontal modal components). Therefore in this analysis, the vertical dynamic response is less than the static response.

Since the effective mass of the vertical component is so low (only $3 \%$ of that of the horizontal component), it is justified to carry out the equivalent static analysis for the spectral loading beyond the cut-off frequency, viz., 33.0 Hertz. The ZPA of the vertical spectrum at 33.0 Hertz is $0.81 \mathrm{G}$. With the reduction factor 0.6667 specified in this calculation, the actual ZPA becomes $0.54 \mathrm{G}$. The static dead weight responses were computed with $1.0 \mathrm{G}$ vertical gravitation load. Therefore the corresponding dynamic responses to the $0.54 \mathrm{G}$ ZPA can be obtained by multiplying the static responses by the factor 0.54 . Adding $54 \%$ of the vertical static responses to the dynamic results, the final dynamic responses are as follows: 
* Maximum Von Mises stress in shells:

Dynamic with 26 modes: 1,694.1 psi

Static with dead weight: 446.4 psi Total

$2,140.5$ psi

* Maximum Shear stress in beams:

Dynamic with 26 modes: $2,754.7$ psi

Static with dead weight: $1,468.0 \mathrm{psi}$ Total $\quad \mathbf{4 , 2 2 2 . 7}$ psi

* Maximum principal stress in beams

Dynamic with 26 modes: $2,955.3 \mathrm{psi}$ Static with dead weight: $\quad 401.4$ psi Total 3,356.7 psi

Maximum Dynamic Displacements
$D x=0.1163$ inches
Node 2233
the plenum
Dy $=0.1297$ inches
Node 2051
$\mathrm{Dz}=0.0374$ inches
Node 5174
middle of roof mid of sidewall

As suggested by Reference [7], the dynamic responses were obtained through the response spectrum analysis with the first 26 eigenmodes included. According to the frequency analysis ( see Table 7 ) only the first 13 eigenmodes are needed to cover the frequency spectrum up to $33.0 \mathrm{Hertz}$. In the dynamic modal spectrum analysis, therefore, 13 additional eigenmodes beyond the cut-off frequency 33.0 Hertz were augmented. As far as the vertical components are concerned the superposition of $54 \%$ of the static responses is quite conservative.

After the adjustment of the dynamic responses due to the ZPA effect the dynamic reaction forces at the base of the $F C$ increase significantly and the uplifting situation of the FC during a seismic event is worse. The number of down-holding nodes is reduced from 81 to 34 . The total dynamic reaction force increased from 35,642 lbs. to 47,828 lbs. 


\subsection{Suggestions}

The stress distribution and deformation of the $\mathrm{FC}$ are functions of the stiffness, mass distribution, and boundary conditions. In this scoping analysis the Plenum moneling is conservative but not as detailed as the rest of the model. Including the conceptual modification with heavy beams and columns in this model made the FC much stiffer and increased its fundamental frequency.

To have an understanding of the seismic capacity of the existing asbuilt FC, an analysis without the conceptual modification should be considered. This recommendation will provide an assessment of the seismic ruggedness of the existing FC. Also, as the results of the present model analysis indicate, the stress level and deformation are quite low. The existing FC with the same boundary conditio s as the present model may be able to sustain the seismic excitations.

Since the overall stress and deformation of this model is low, and the actual base boundary condition does not hold every point to the raildolly as prescribed, a relaxation in boundary constraints, inclusion of nonlinear interfaces in the model, and a nonlinear dynamic time history analysis may be more realistic for the "as is" FC. 


\section{REFERENCES}

1. Communications between DuPont and WSRC Engineers:

1. May 8,1987

To: S. R. Norbutas (AED)

From: J. M. Cahill (Allstates)

2. December 2, 1987

S. F. Petry: Filter Compartment Seismic Resistance.

3. March 15, 1988

To: R. S. Varney (AED/Allstates)

From: J. M. Cahill (AED/Allstates)

4. April 20, 1988

To: R. D. Kelsch (AED)

From: R.S. Varney $(\mathrm{A} / \mathrm{S})$

5. May 18,1988

To: R. D. Kelsch (AED)

From: G. J. Tsavalas (AED)

6. May 19, 1988

To: A. C. McCullin / L. Golden (AED)

From: R. D. Kelsch (AED)

7. June 17,1988

To: G. C. Cambre

From: R. J. Thomas / J. M. Cahill (A/S)

9. November 16,1989

To: K. M. Vashi (WSRC)

From: J. M. Cahill (DuPont)

2. March 20, 1990. Inter-Office Memorandum

To: Chung Gong

From: K. M Vashi

3. Shop drawings: BPF 211147, drawing number FD-405-001 to 026.

4. June 29, 1990 . Inter-Office Memorandum

To: Chung Gong

From: K. M. Vashi

5. Seismic Qualification Program, Savannah River Site Reactor Facilities, Program Plan and Procedures, January 1990, Seismic Engineering, WSRC.

6. Chung Gong: Geometric Properties of cross-sections of Beams and Columns in the Seismic Analysis of Filter Compartment. 
7. August 7, 1990. Inter-Office Memorandum EPD-SE-90-0018:63 To: Chung Gong From: Ed Estochen

References [2], [4] and [7] are attached to this report in Appendix B. 


\section{ACKNOWLEDGEMENT}

Dr. Kiranchandra M. Vashi of Seismic Engineering, suggested this problem and the general technical approaches in solving this problem as indicated in his memoranda 121,14$]$. We sincerely appreciate his contribution in the analysis. 


\section{APPENDIX A}

\section{A.1 Test Runs}

A.1.1 A complete half model with fixed base was used for testing the computer capacity and ABAQUS's reliability in Frequency Analysis. Several unanticipated problems arose when ABAQUS jobs were submitted. Initially, the UNICOS script file which submits ABAQUS jobs on the CRAY had to be optimized to handle the large memory requirements of this model. This took place only after a lengthy troubleshooting period. When this problem was solved, CPU intensity of the analysis emerged as a severe problem. This was affected by the large amount of input/output activity required by the model. A bug in the PATRAN to ABAQUS translator had added to this problem by translating the beam properties incorrectly. The approximately 60 unique properties were being translated into approximately 550 different property sets. The resolution of this problem required the creation of a supplementary FORTRAN program to compare these values and output a list of property sets which could be combined. This combination had to be done manually. A few successive runs indicated that ABAQUS was able to carry out the Frequency Analysis. Most of all, the test run produced confidence that even though the model was only half the real model, it was sufficient in structural details. The fundamental frequency was 2.3 Hertz which is quite reasonable under the given boundary conditions.

A.1.2 In this second test run, we adopt the same half model as was previously used. However, the boundary conditions are more realistic. The bottom of the FC is vertically restrained except at the lucation of the Guide Cone where the node is fixed in all three directions. The center plane which separates the whole model in halves along the two nozzle axes is prescribed with symmetric boundary conditions with respect to the Z-axis that is normal to the side walls of the FC. The nozzles are allowed to slide and rotate along their axes but otherwise they are continuous with the exhaust pipes from the reactor building wall.

The first three frequencies, namely 5.0918, 13.181, and 14.991 Hertz correspond to the first three symmetric modes. In this run, the Response Spectrum Analysis was performed to provide useful reference data for the Full Model Analysis. 


\section{A.1.3 Dynamic Analysis of Full Model without MPC's}

This is the first complete FC finite element model with all the details except the MPC's which connect the shell elements with the beam and column elements. The calculation provides satisfactory results. This analysis virtually recaptures the symmetric modes obtained in the half model calculation. The Von Mises stresses in shell elements are well below $5 \mathrm{ksi}$. 
APPENDIX B

$-23-$ 
$3 / 20 / 90$

To.

DR. CHUNG GONG $5 R L-773-42 A$

FRom: KIRAN VASHI

SETSMIC Encrinezerina

SUBJezt: General Aontlysis Rezuikenewts for Confinement flltex

Enclused PLEASE FIND A Document ON THE ROXERENCED SUBSTET. THIS Deument is to BE Fouconzes in THE FILTEX DYAAMIC MOSEZLIMT AnS Aorteysis wORK DIAT YOU ARE

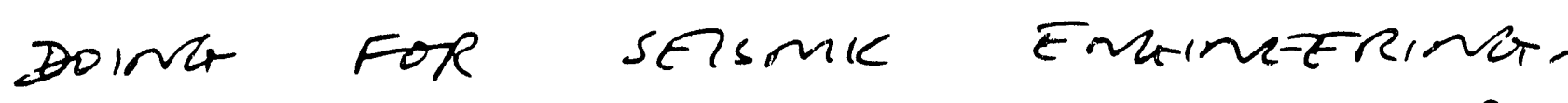
If You have ANY Q vastions, PLEASE CALL MẼ.

Trury yours,

$$
\text { K.M.Vos Lin }
$$

CC: M.W. BARLOW, 703-25C R. BELNEYER, SRL-773-42A 
DRAFT

GENERAL ANALYSIS REQUIREMENTS

FOR

CONFINEMENT FILTERS

BY

KIRAN M. VASHI

MARCH 6, 1990 


\section{TABLE OE CONTENTS}

SECTION

1.

2.

3.

3. 1

3.2

3.2 .1

3.2 .2

3.2 .3

3.2 .4

3.3

3.3.1

3.3.1.1

3.3.1.2

3.3.1.3

3.3.1.4

3.3.1.5

3.3 .2

4

5

6
DESCRIPTION

Introduction

Scope

Seismic Analysis

Method

Modeling

Stiffness

Mass

Damping

Boundary Conditions

Modal Response Spectrum

Method

Unidirectional Shock

Multiply Supported System

Number of Modes to be

Considered

Modal Combination

Effect of Higher Modes

Combination of Responses from

Lower and Higher Frequency

Modes

Combination of Earthquake

Components

ABAQUS Computer Program

Documentation of Model and

Analysis Results

References
PAGE

3

3

3

3

$3-4$

4

4

4

5

5

5

5

5

5

5

6

6

6

6

7 


\section{INTRODUCTION}

This document provides general analysis requirements for Savannah River Site (SRS) confinement filters. The filters are part of an Airborne Activity Confinement System (AACS). These filters absorb a significant amount of radioactive effluents in case of an incident before exhausting the filtered air to the atmosphere via the stack. The purpose of the analysis is to ascertain the seismic adequacy of the filters for a $0.2 \mathrm{~g}$ Design Basis Earthquake (DBE).

\section{SCOPE}

The document specifies general analysis requirements for the SRS filters. The requirements encompass modelling, use of computer codes, modal response spectra analysis, modal combination, damping and output.

\section{SEISMIC ANALYSIS}

\subsection{METHOD}

The confinement filter shall be analyzed by the modal response spectrum method using the ABAQUS computer program.

\subsection{MODELING}

For the modal response spectrum method of analysis, a mathematical dynamic finite element model of the asconstructed ( or as-built) filter shall be developed to represent and simulate dynamic interaction of the nozzles, outer shell, upper and lower compartments, filter frames, filters, access doors and supports system. The model shall be prepared with a sufficient amount of detail to permit evaluation of stresses in members of the confinement filter, loads in supports and possibility of effluent bypass around the filters. The model shall account for the following: 
- Stiffness

- Mass

- Damping

- Boundary Conditions

These parameters shall be derived from the basic material properties, design and construction characteristics, drawings and other applicable documents and specifications.

\subsubsection{STIFFNESS}

The stiffness characteristics of various component parts of the filter shall be calculated using the applicable drawings. The component parts shall be represented by the appropriate finite elements of the ABAQUS program.

\subsubsection{MASS}

The mass properties shall be represented by the lumped mass and associated rotational inertia discretized at the nodes of the model. Alternatively, or in conjunction with the lumped mass approach, consistent mass formulation may be used.

Mass shall be lumped so that the total mass, and the location of the center of gravity are preserved both for the structure and its components. The number of dynamic degrees of freedom and hence the number of lumped masses shall be selected so that all modes of vibration with frequencies less than $33 \mathrm{HZ}$ are accurately accounted for.

\subsubsection{DAMPING}

In the modal spectra analysis of the filter, the seismic response spectra for $3 \%$ (Table $2.2-2$ on page 10 of SEP1 in Ref.1) modal damping shall be used. Modal interpolation shall use the specified scale on the spectrum plot (e.g. log-log, log-lin, lin-log, lin-lin). 


\subsubsection{BOUNDARY CONDITIONS}

The model shall incorporate appropriate representation of constraints imposed on the boundary due to conical guides, nozzles, anchor hook, upper guide plate and other imposed boundary conditions.

\subsection{MODAL RESPONSE SPECTRUM METHOD}

\subsubsection{UNIDIRECTIONAL SHOCK}

Modal spectra seismic analysis shall be performed for each individual unidirectional shock as follows.

\subsubsection{Multiply Supported System}

Since the filter is seismically excited at multiple input points, the envelope of the spectra at all attachment points shall be used

3.3.1.2 Number of modes to be considered.

Modal responses for all modes below $33 \mathrm{HZ}$ shall be included in computing the resultant response.

\subsubsection{Modal Combination}

The modal responses for all modes below $33 \mathrm{HZ}$ shall be combined using the square-root-sum-of-squares (SRSS) procedure (paragraph E on page 6 of SEP-1 in Ref. 1).

\subsubsection{Effect of Higher Modes}

The effect of higher modes with frequencies greater than or equal to $33 \mathrm{HZ}$ shall be computed and accounted for using the Zero-Period-Acceleration (ZPA) method which uses the ZPA to perform static analysis in each direction of seismic shock. The ZPA is the spectral acceleration at $33 \mathrm{HZ}$ unless a different frequency is justified. 
3.3.1.5 Combination of Responses from Lower and Higher Frequency Modes.

The resultant response of all lower modes from section 3.3.1.3 shall be combined with the resultant response of all higher modes from 3.3.1.4 using the SRSS procedure.

\subsubsection{Combination of Earthquake Components}

The three components of earthquake shock (two horizontal and the vertical) shall be considered to act simultaneously. The seismic response from section 3.3.1.5 for each individual unidirectional shock shall be combined by the SRSS procedure to obtain the response due to three components acting simultaneously.

\section{ABAQUS COMPUTER PROGRAM}

Controlled, verified and validated version of ABAQUS shall be used. The analysis results shall be certified to document use of such a version of the ABAQUS code.

\section{DOCUMENTATION OF MODEL AND ANALYSIS RESULTS}

The finite element model shall be validated and documented in terms of definition of nodes, elements and element and material properties. The input for the model shall be preserved and supplied in the form of plots, and data on hard copy and magnetic tape for future use. A general description of the model and its documentation shall be also provided.

The analysis results shall be documented in terms of the list and and purpose of runs, and validation of computer runs and the results. The results shall be supplied in the form of frequencies, mode shapes, stresses, displacements and forces and moments in the elements representing the structural members and supports of the filter. 


\section{REEERENCES}

1. Seismic Qualification Program, Savannah River Site Reactor Facilities Program Plan and Procedures, January 1990, Seismic Engineering, WSRC. 
ENGINEERING AND PROJECTS DIVISION

SYSTEMS ENGINEERING DEPARTMENT

EPD-SE-90-0010:61

DATE: JUNE 29, 1990

TO: DR. CHUNG GONG, SRL

FROM: K. M. VASHI, 703-25C, 7-9071 K.M.V.

\section{SUBJECT: SEISMIC ANALYSIS INPUT FOR FILTERS}

With respect to the filters seismic analysis, this letter documents the analysis input as follows:

A. Weights of Filters

see Attachment \#A

B. Seismic Spectra

see Attachment \#B

* Please multiply the spectral accelerations in Attachment B by a factor of 0.6667 before inputting them to the model.

Please note the North $(\mathrm{N})$ direction is perpendicular to the two rails for $K$ and $P$ reactors and is parallel to the two rails for $L$ reactor. Therefore, to perform one conservative generic analysis for all three reactors, please envelope the spectra for North(N)-South(S) and East(E)-West(W) directions and then apply the resulting envelope spectrum in each of the two horizontal (ie. N-S and E-W) directions.

C Distance of Filter from Wall

Mr. R. Schert has confirmed that the correct distance between the face of the wall and face of the filter is $63^{\prime \prime}$.

D. Boundary Conditions

* For each of the two nozzles at the nozzle-pipe interface, the translational displacement along the nozzle axis and the rotation about the nozzle axis are discontinuous. Rest of the 
degrees of freedom at this interface are to be modelled as if the nozzle-pipe interface is continuous.

- For conservatism and linearization purposes, the restraint due to latch between the two nozzles, the upper guide and the dog legs (lower guides) is not to be included.

- At the interface between the filter base and rail-dolly the horizontal deflections along and perpendicular to the rails at each of the two guide cones is to be set to zero.

* Based on preliminary indication and for linearization purposes, the filter base locations, at which vertical deflection is to be set to zero, are as shown on Attachment C.

If you have any questions, please call me.

\section{$\mathrm{KMV} / \mathrm{jb}$}

cc: Roy Funderburk, SRL

Russ Beckmeyer, SRL

M. W. Barlow, 703-25C

R. Scherr, 707-C

M. E. Maryak, 703-25C

G. A. Antaki, 703-24C

R. S. Hoskins, 703-24C 


\section{Aterenment \#A}

Westinghouse Savannah River Company

Inter-office Memorandum

OPS-RSE-901264

June 20,1990

To: Kirhan Vashni

From: Rod $\boldsymbol{W}$. Scherr

Weight of Filter Compartment Components

Component

Carbon cell

particulate flt

Demister cell

\section{SOURCE OF INFORMATION}

Vendors QA Report

Shipping Weight

Call to vendor
VALUE

$1401 \mathrm{lbs}$

50 lbs

11 lbs 


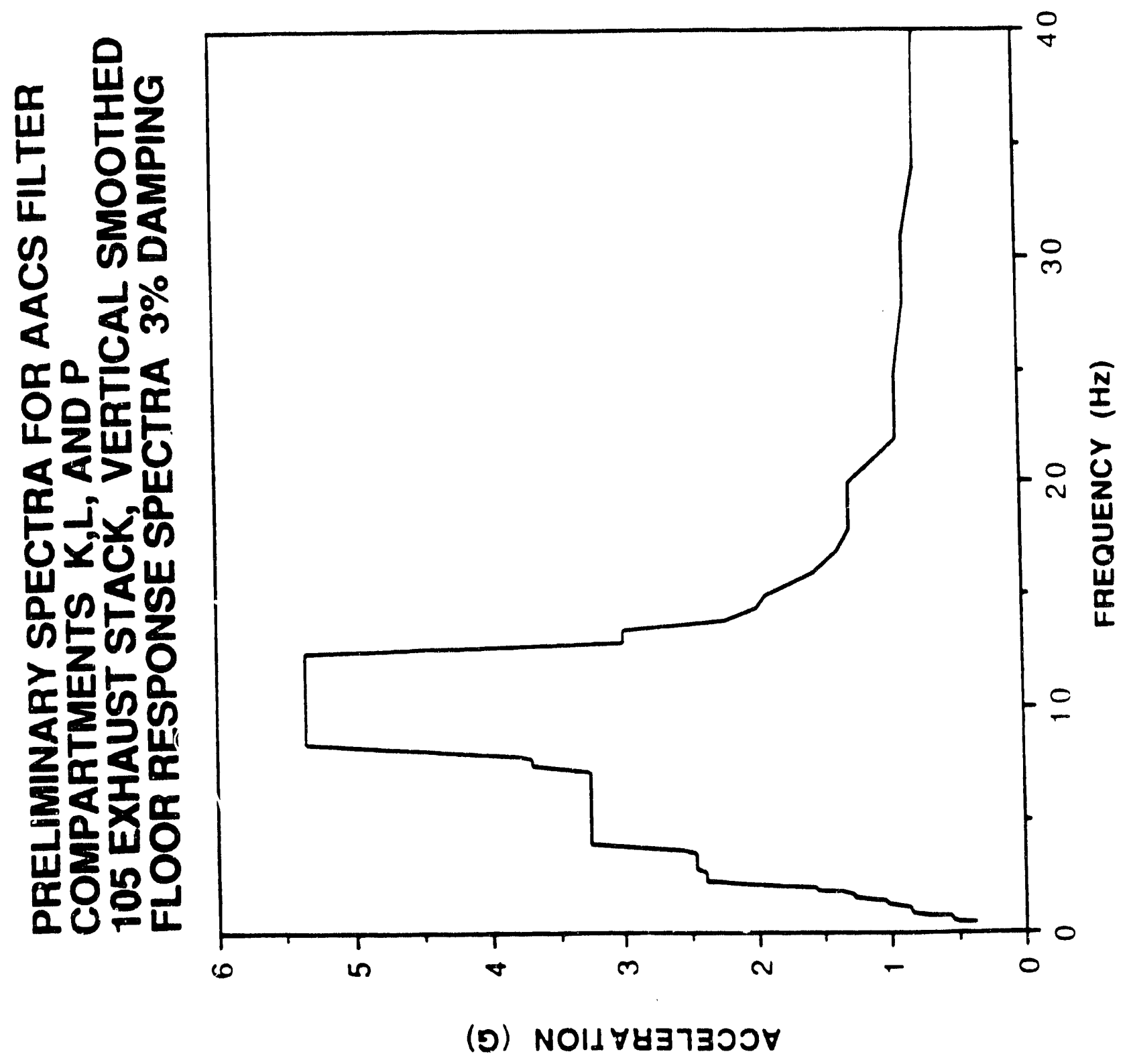



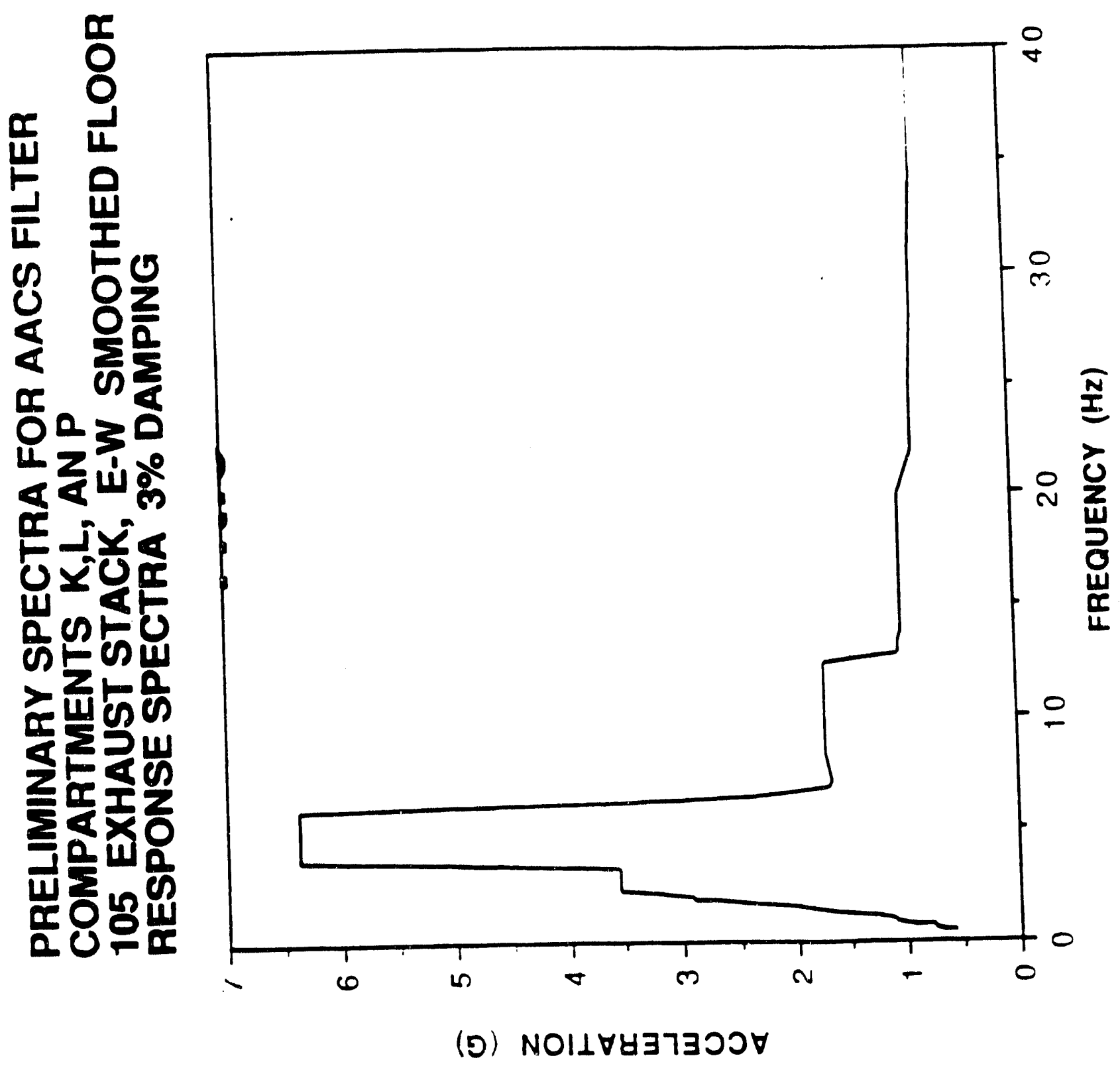

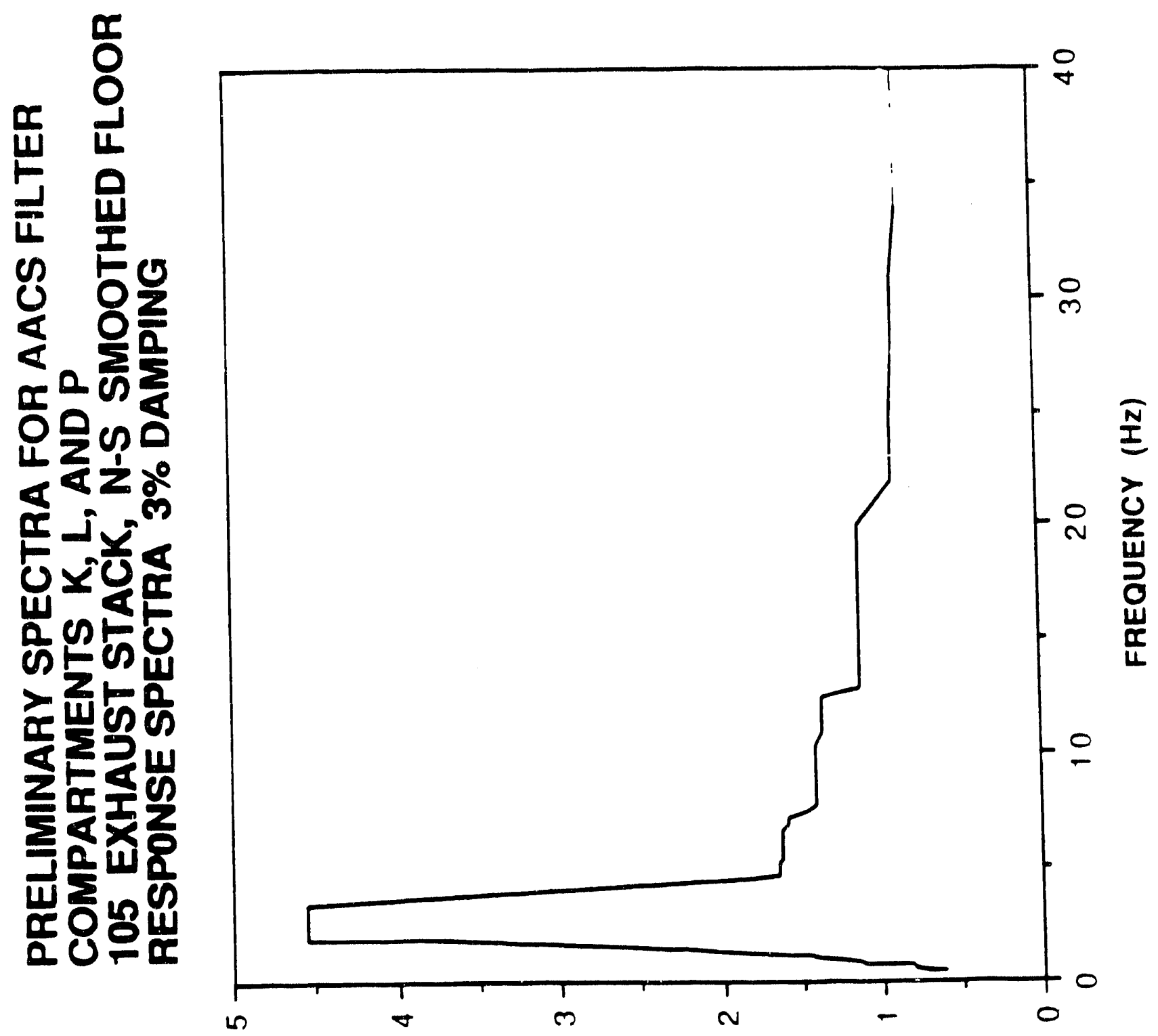

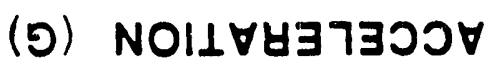




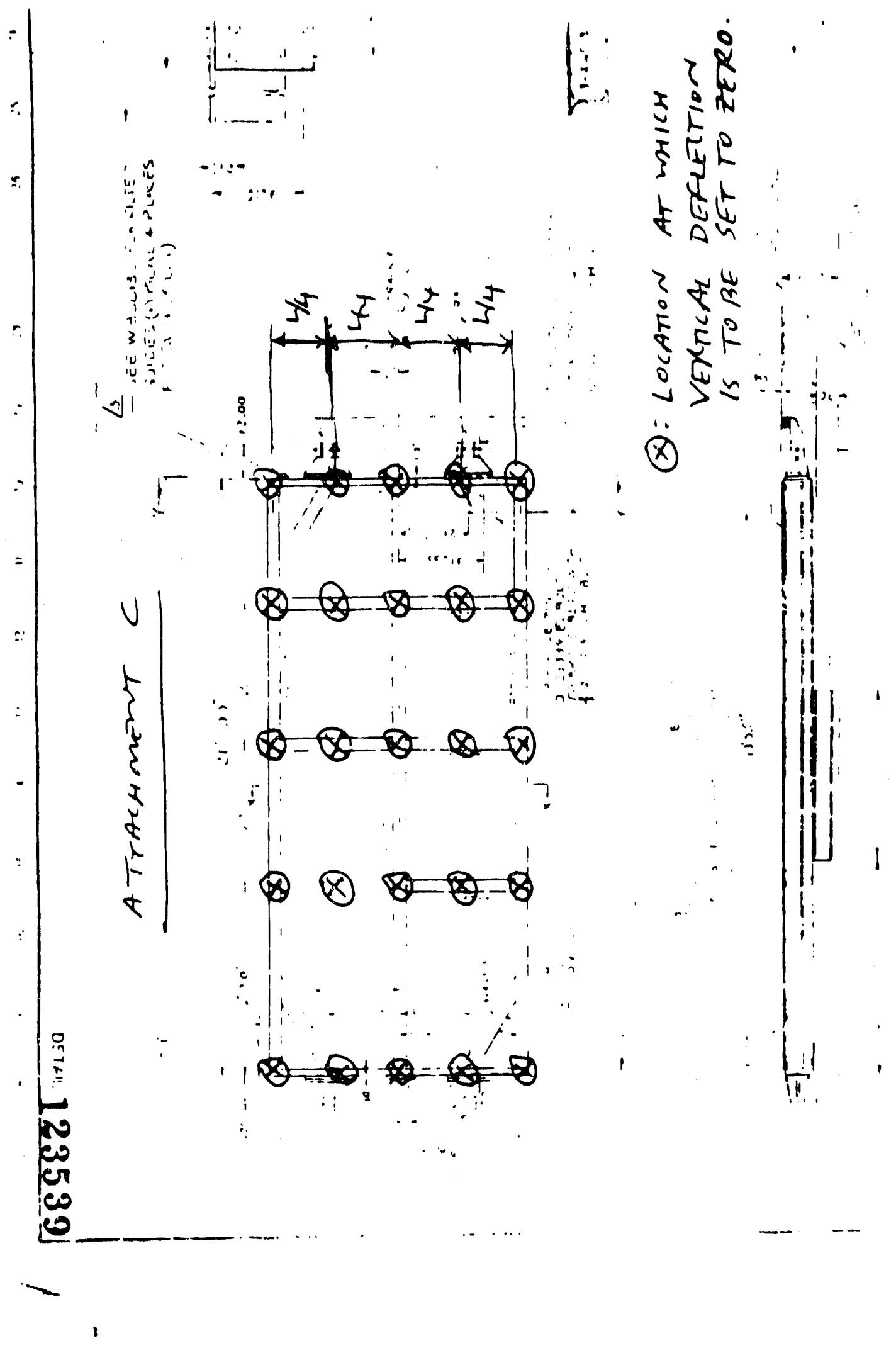


WESTINGHOUSE SAVANMAH RMEA COMPANY INTER-OFFICE MEMORANDUM

May 10, 1990

TO: Stan Petry, SRL $(773-41 A)$

From: R.S. Hoskins, $(703-24 C)\{\hat{X} \phi 4$

\section{AAC8 PIITER COYPARTYOHYR}

As agreed upon in our meeting of March 3, 1990 on the subject, the three attachments to this letter provide you with the information you need to set the requirements for the filter compartment.

The first attachment presents the amplified floor response spectra for $E-W$ Horizontal, $N-S$ Horizontal, and Vertical accelerations at El. 55' for the 105-K Stack Building. The input was a $0.2 \mathrm{~g}$ 2PA. R.G. 1.60 Ground spectra with an amplication of factor 2.0. being applied. A amplication factor of 2.0 was used to provide margin for a potential increase of the ground response spectra to a $2 P A=0.39$, a seismic motion input at a higher elevation (El.66') on the inlet \& outlet nozzles, and the differences in the response spectra in $L$ \& $P$ Reactors. This assures the spectra given will envelope all possible contingent cases for the filters.

The second attachment presents SEP-22 which invokes IEEE-344-1987 as the seismic qualification methodology standard to be used. This procedure provides the exceptions to the standard permitted for the SRS Reactors.

The third attachment is provided for information purposes explaining the approach used by SRI for performing a finite element analysis using the ABAQUS computer code.

The fourth attachment provides the seismic qualification approach to be used for the redesign of the filter housings.

If you have any questions regarding this matter, please feel free to contact me at $\times 7-6422$ for help on this subject.

CC: M.W. Barlow, 703-25C G.A. Antaki, 703-24C File 16.8

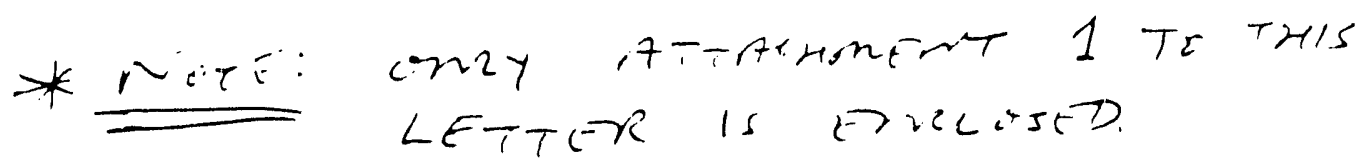




\author{
ENGINEERING \& PROJECTS DIVISION \\ SYSTEMS ENGINEERING DEPARTMENT
}

EPD-SE-90-0018:63

DATE: August 7, 1990

TO: Chung Gong SRL

FROM: Ed Estochen BTC-B15

It is not necessary to do an equivalent static run, using the filter compartmer: finite element model, to obtain the higher mode participation. Including more modes in the spectral analysis will satisfactorily duplicate the combination of the dynamic stresses with the equivalent static component representing the contribution from the higher modes. The number of modes included should be such that at least $90 \%$ of the filter compartment's total mass is participating in the response. Per our meeting (8/6) approximately 40 of $45(88 \%)$ total filter mass units were participating in the response due to the inclusion of 19 modes. If the number of modes is increased from 19 to 25 , the $90 \%$ requirement should be met. If after this increase the requirement is still not met, continue to increase the number of contributing modes until more than 40.5 of the total 45 mass units are participating. This dynamic analysis should be performed on the initial model, for which stresses have already been obtained, before pursuing an analysis using the updated PATRAN model. The desired results from this analysis are the maximum stresses in the beam elements for which the "section points" were specified. These results should be directed to myself and Dick Hoskins at your earliest convenience.

I appreciate you patience and perseverance and hope that this modeling strategy will facilitate the project's completion.

cc:

R. Hoskins, 703-24C

B. Gutierrez, 703-41A

M. Barlow, 703-25C

W. Kennedy, BTC-B15

K. Vashi, 703-25C

R. Beckmeyer, 773-42A

File 16.8 


\section{FIGURES}




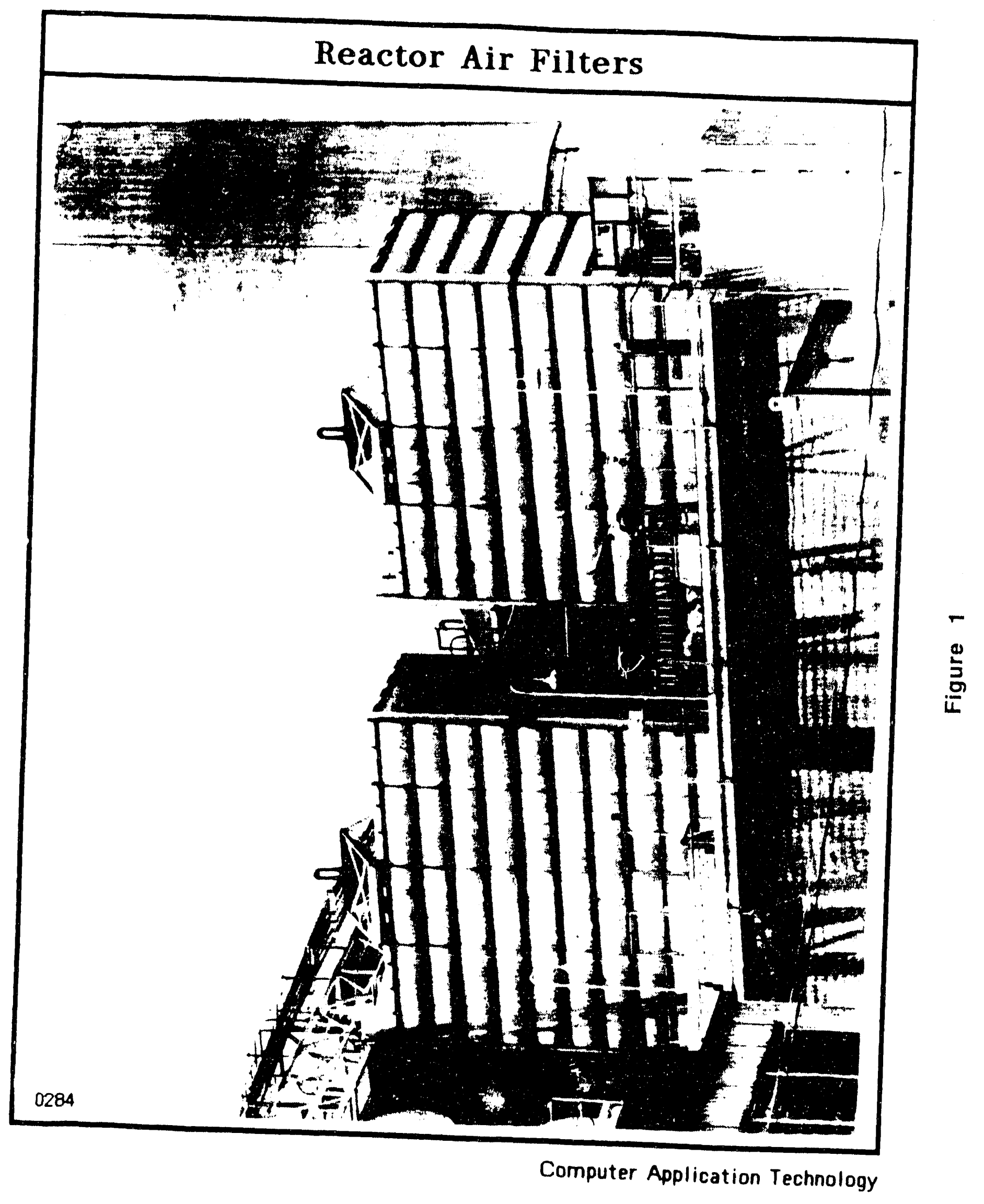




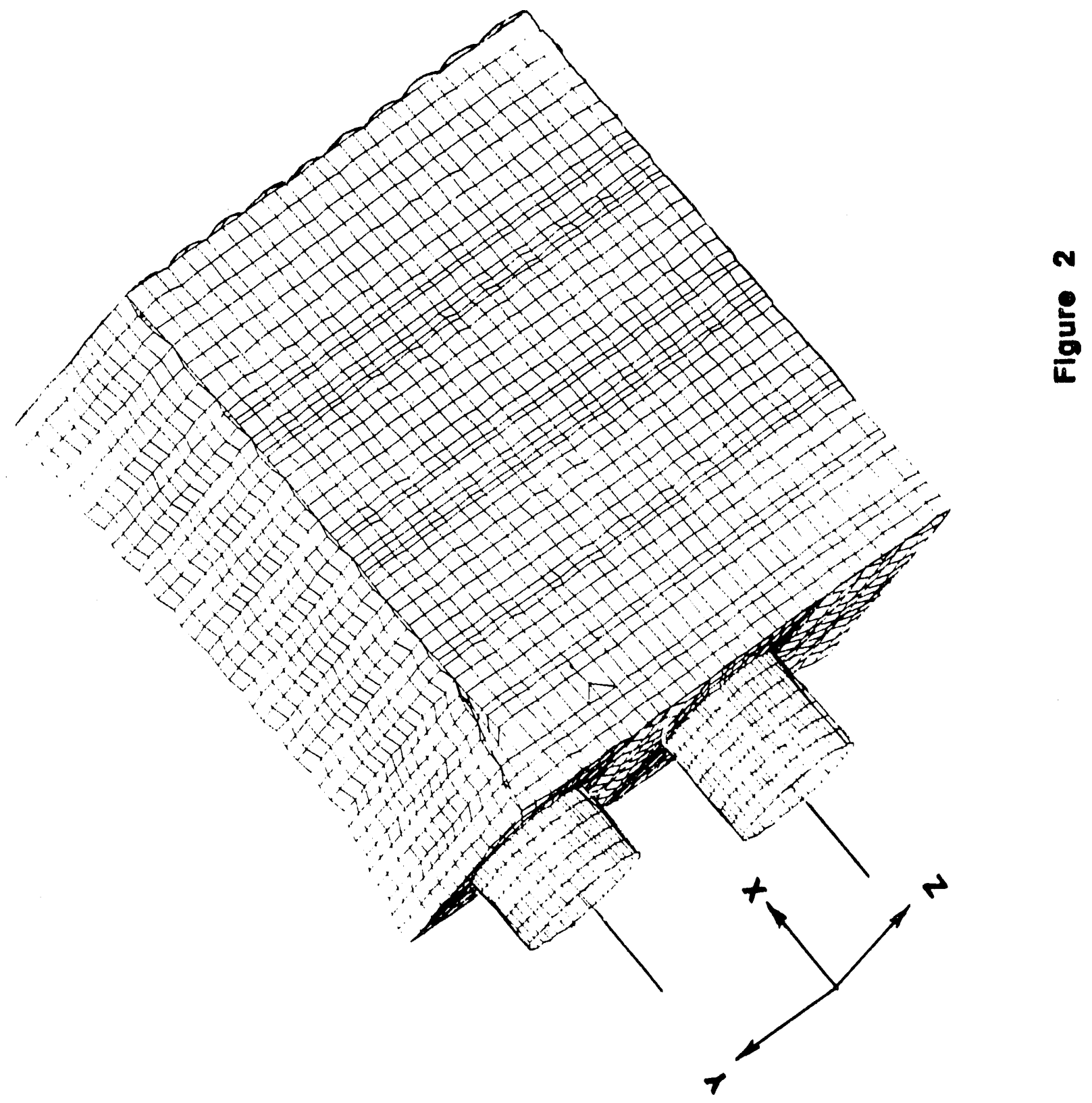




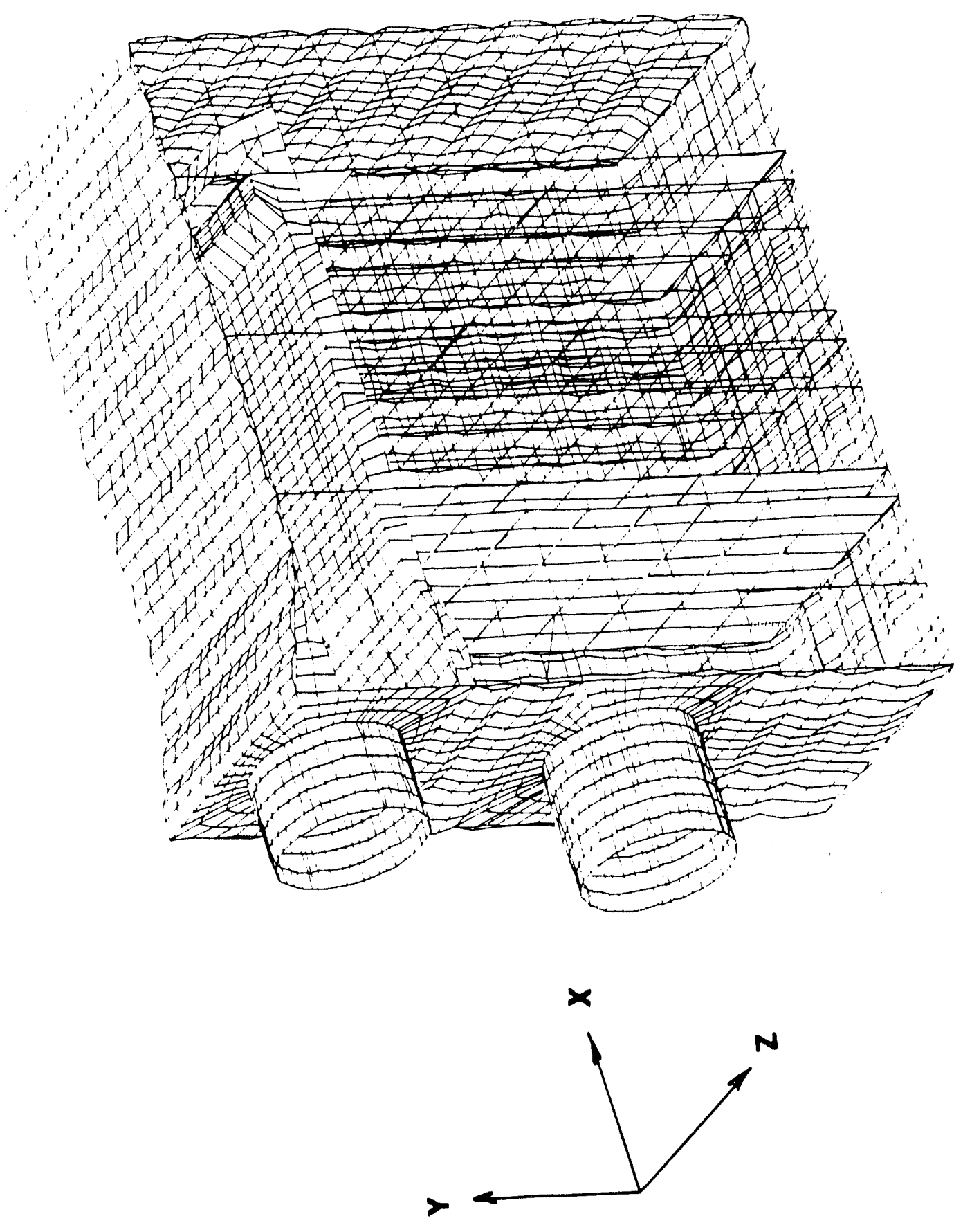




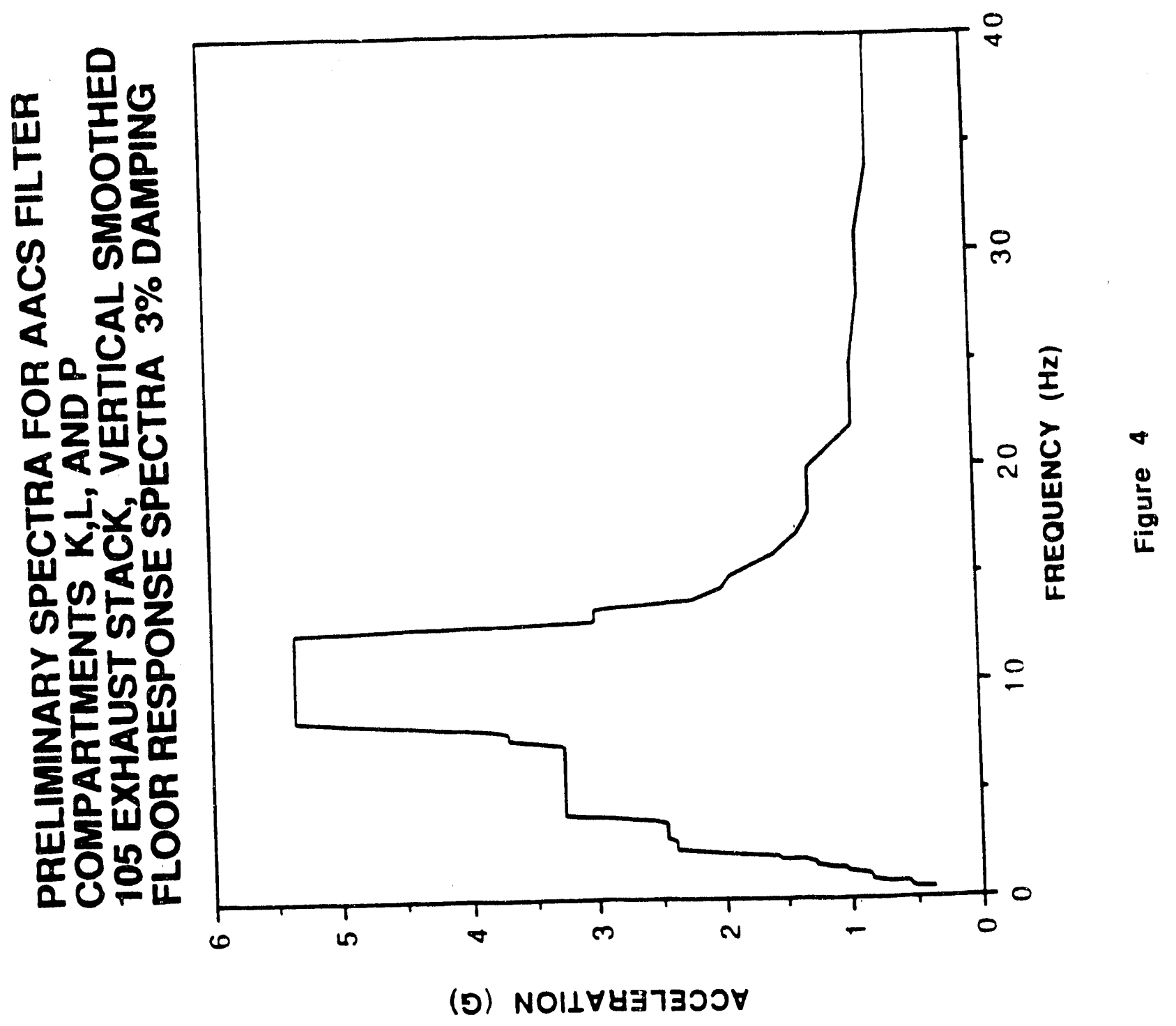




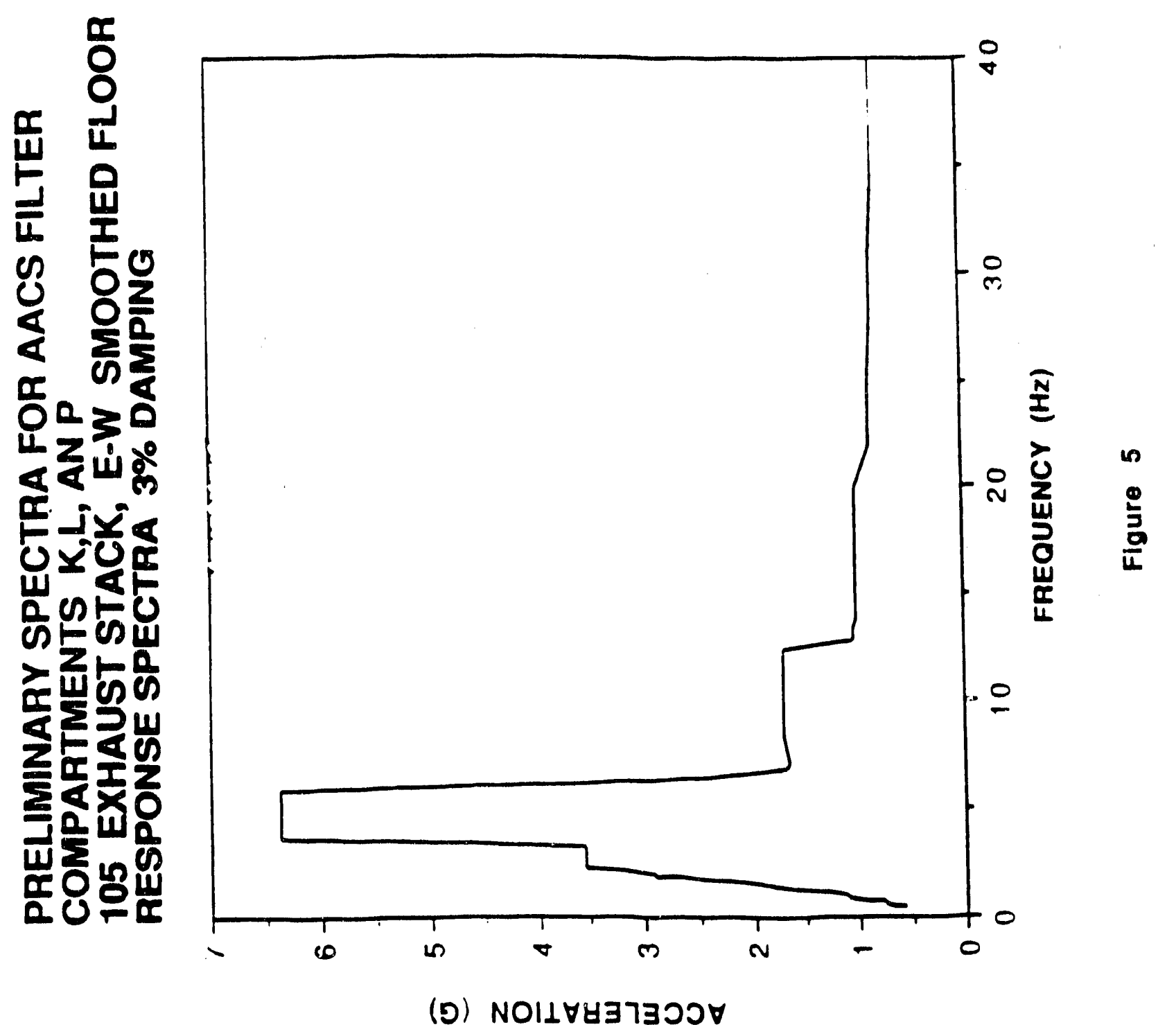



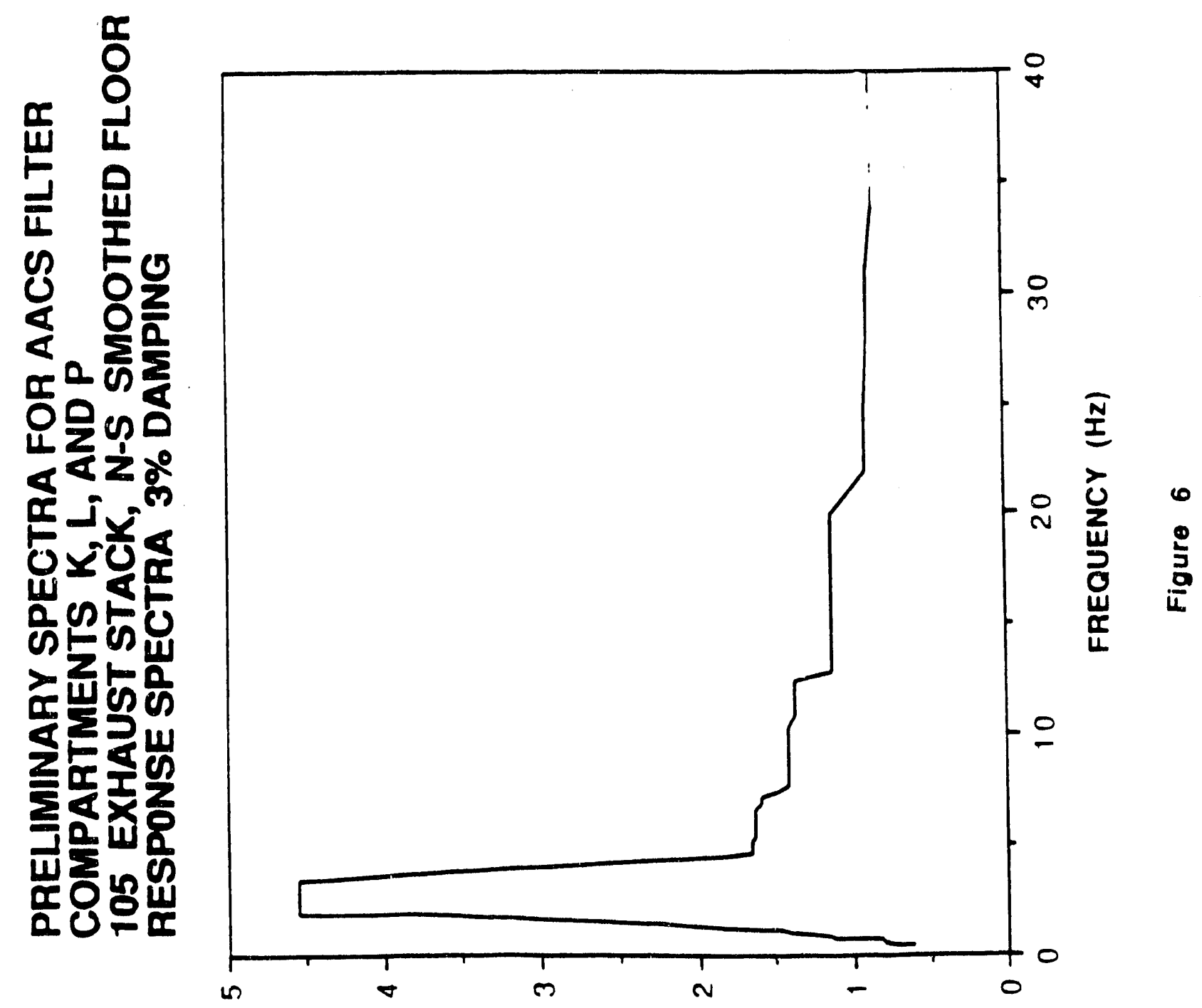

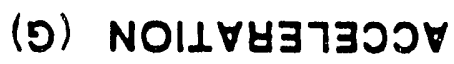




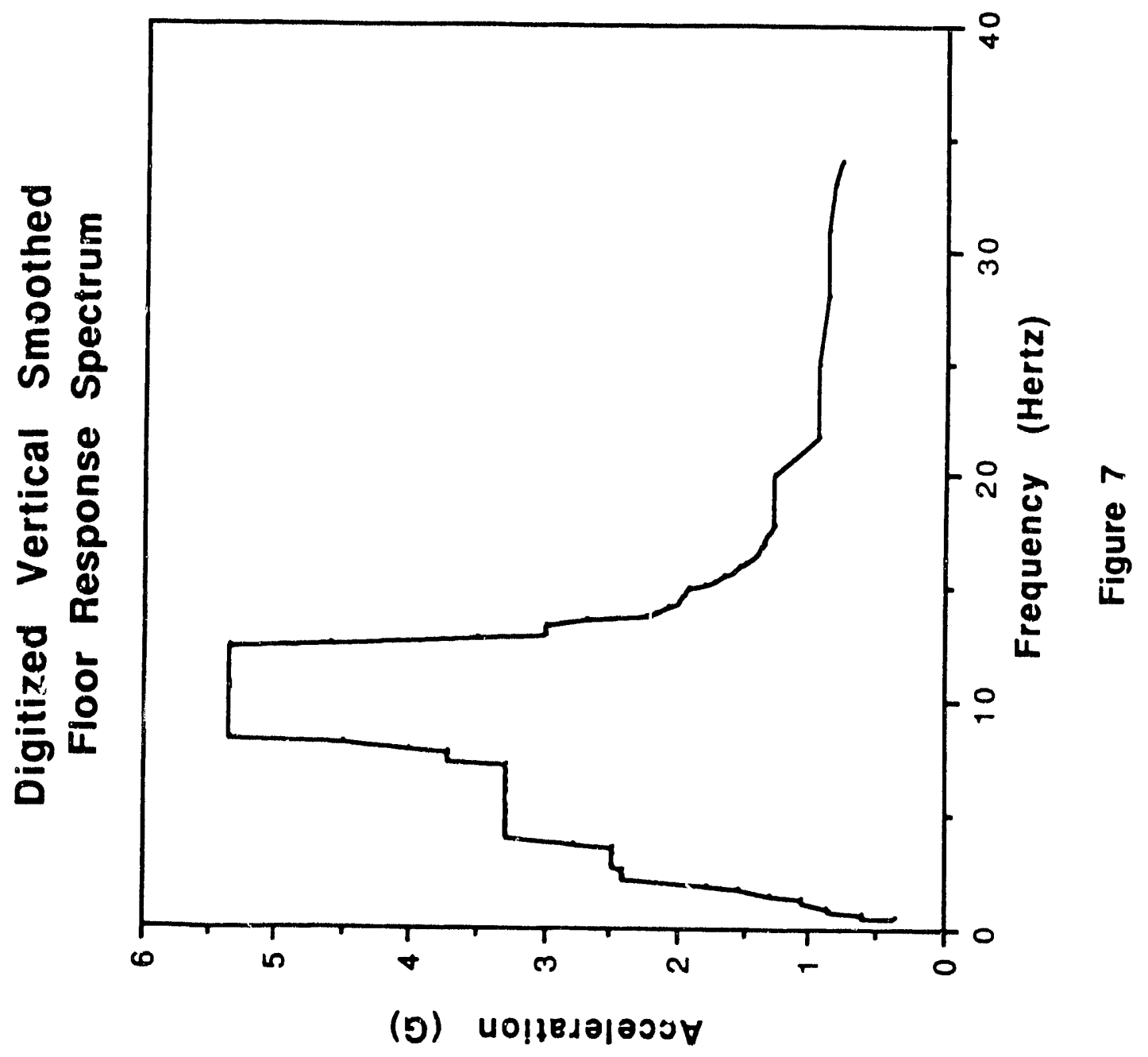




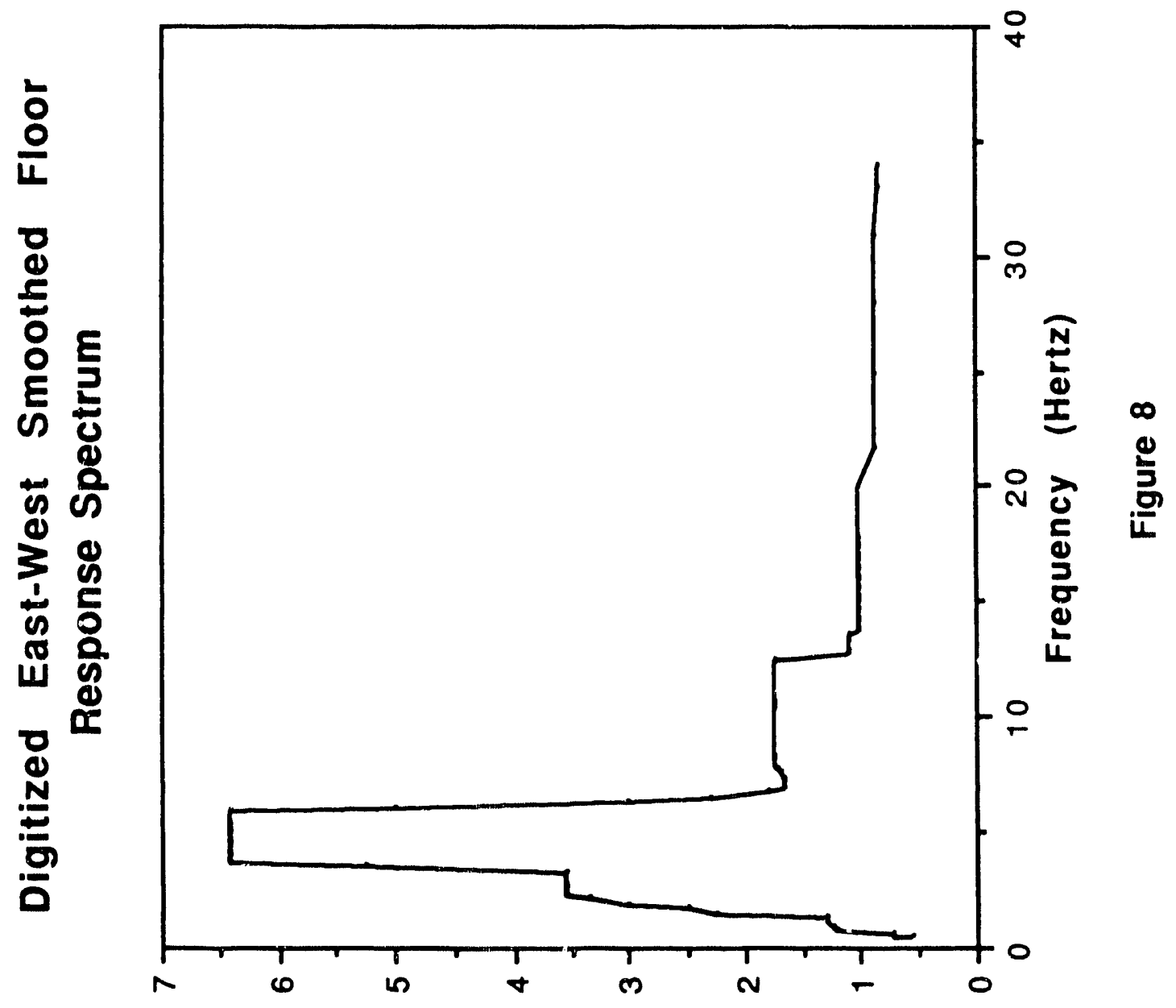

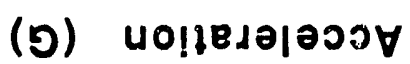




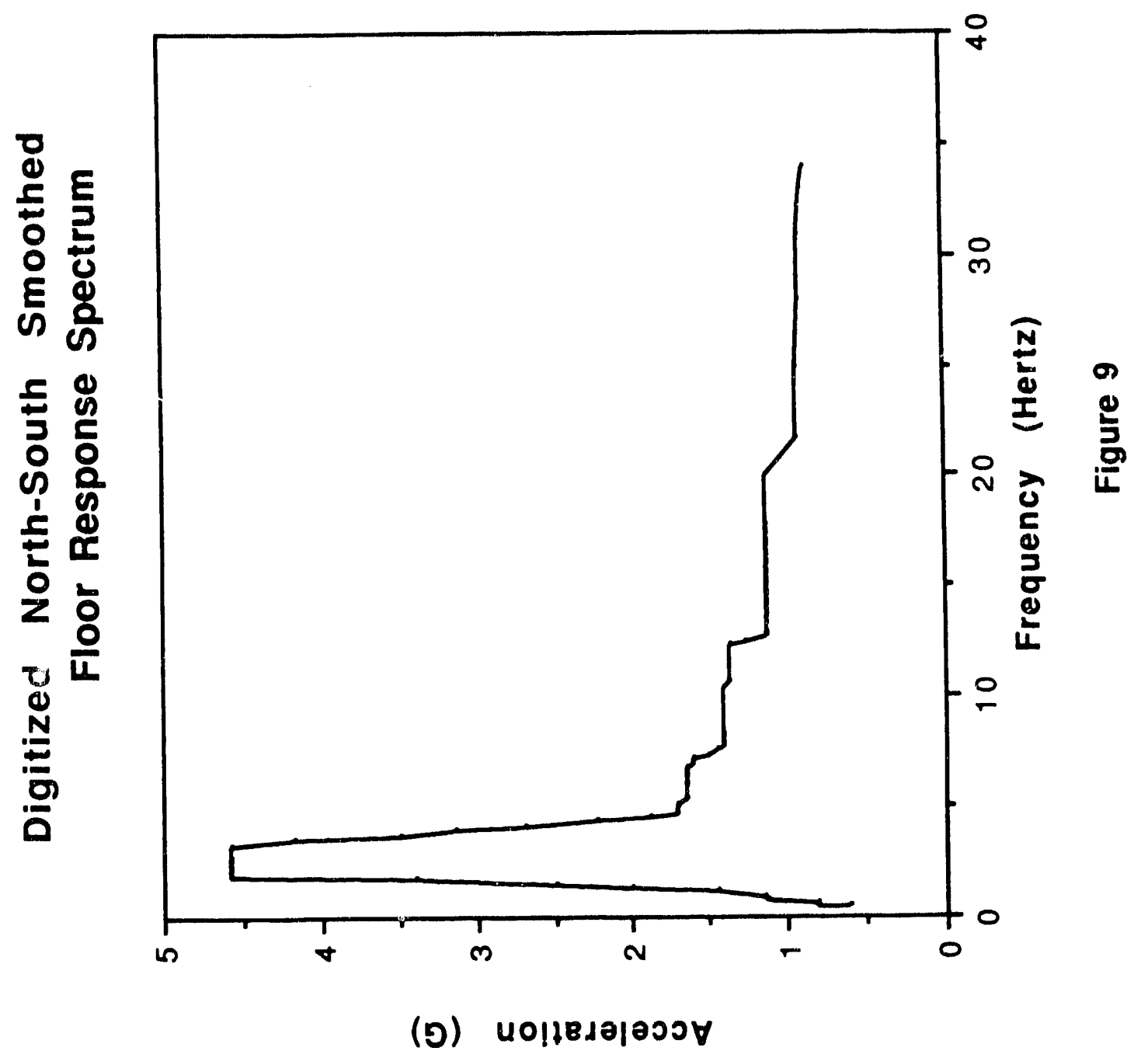




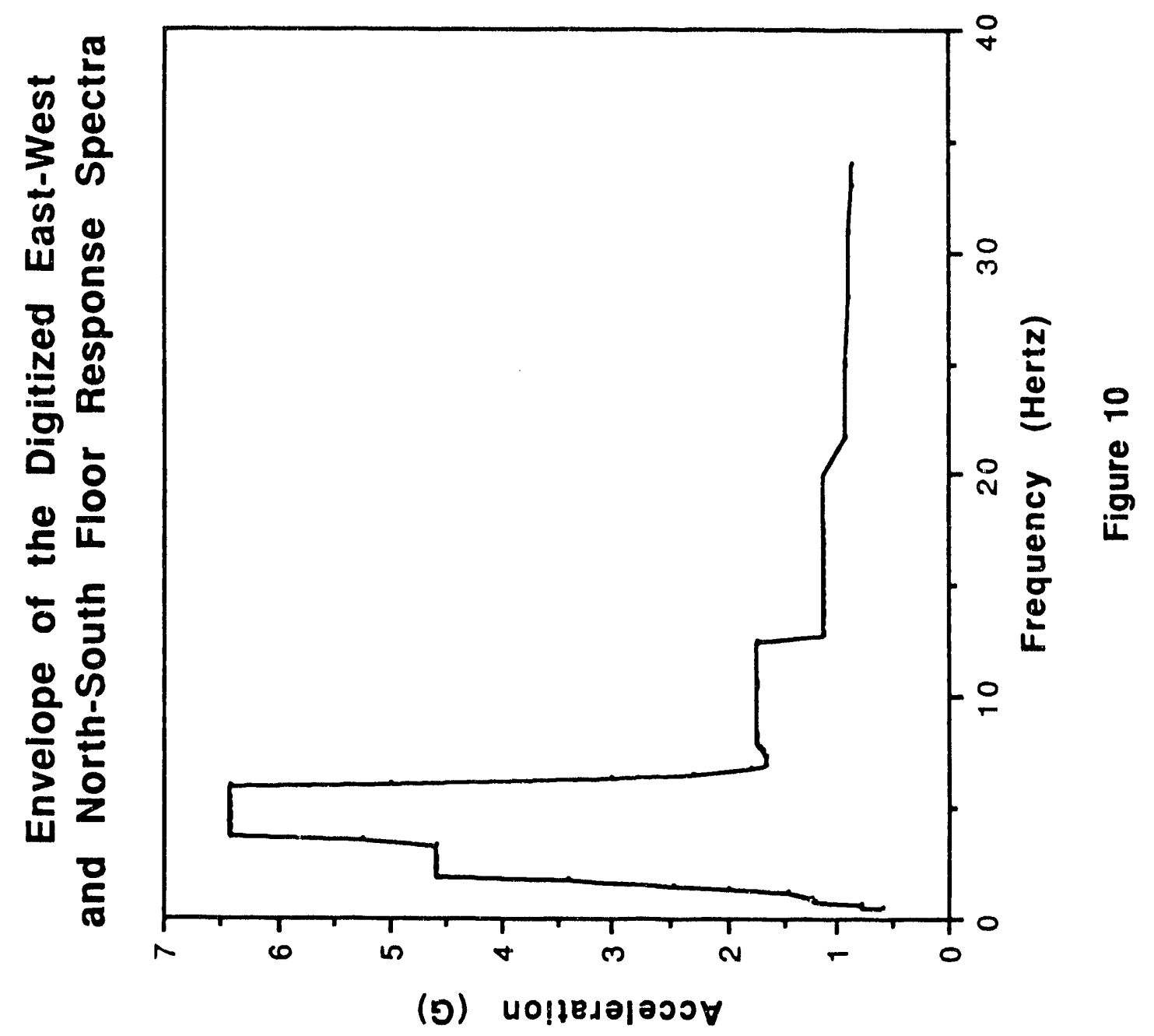



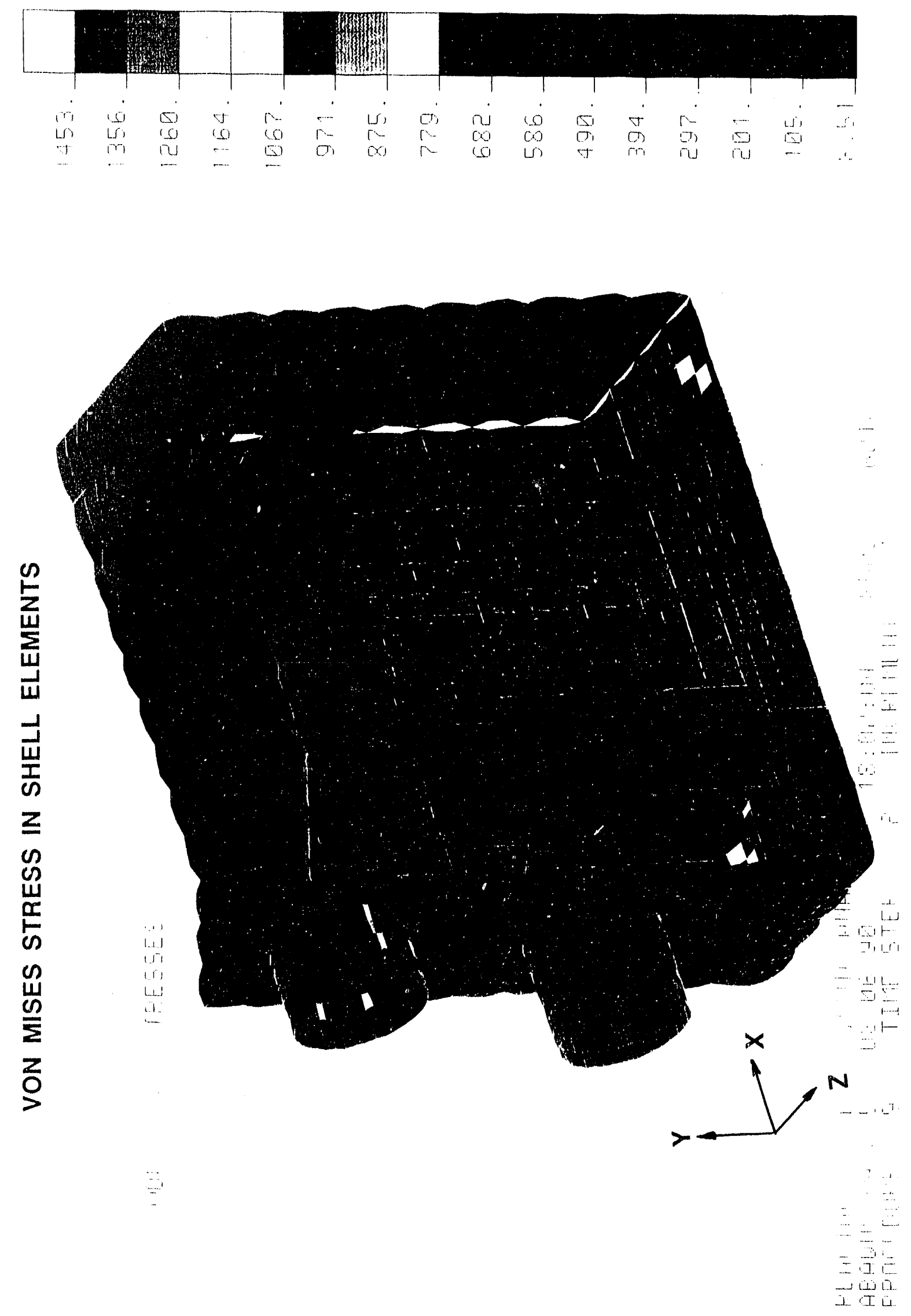

ํ.
은
$\frac{0}{2}$ 


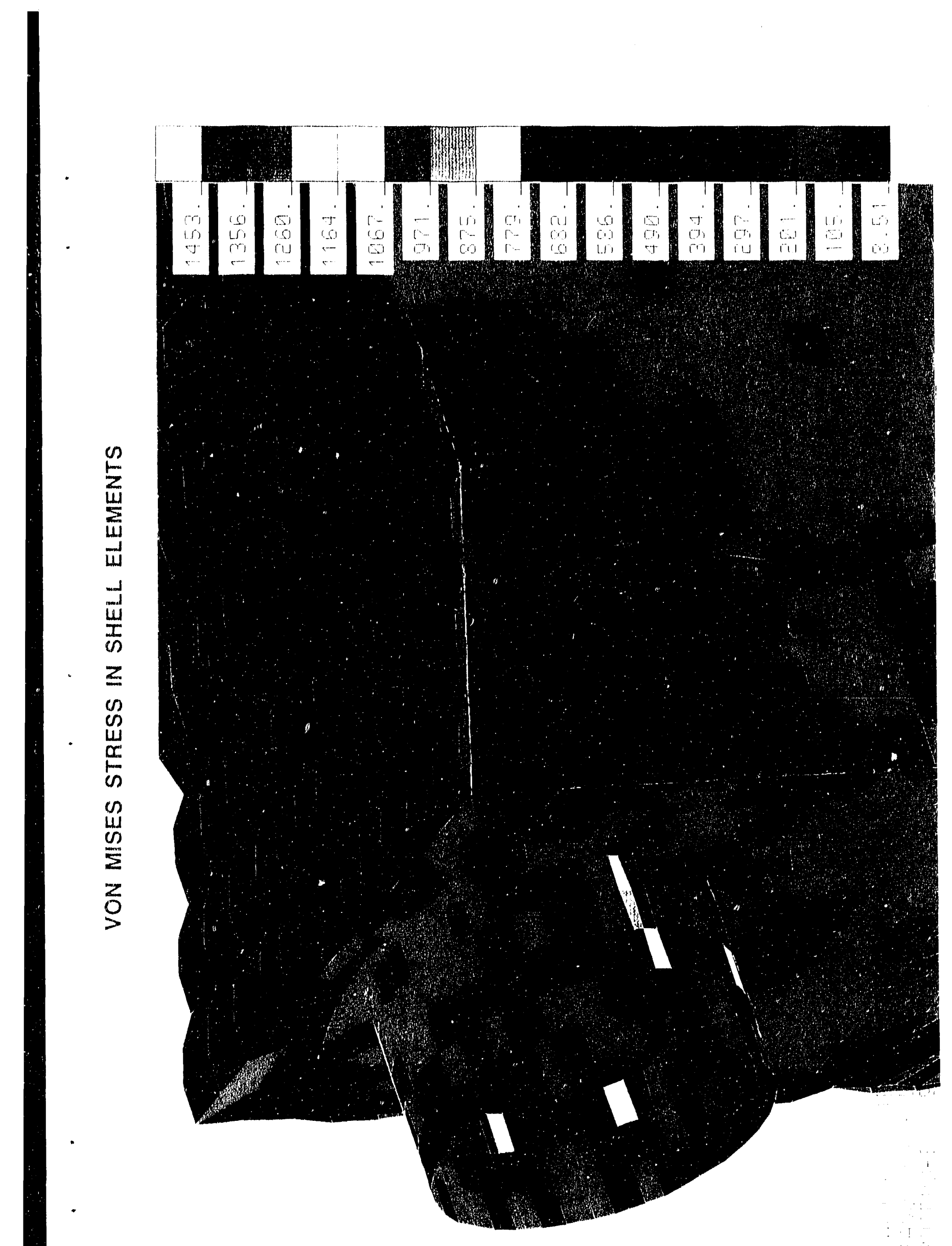

$\frac{n}{2}$ 
TABLES 
Table 1 SECTIONAL PROPERTIES

\begin{tabular}{|c|c|c|c|c|c|c|c|}
\hline MEMBER & SHAPE & AREA & $1 \times x$ & lyy & J & MATERIAL & PAGE \\
\hline NUMBER & & $\mathrm{INCH}^{* * 2}$ & $\mathrm{INCH}^{* * 4}$ & INCH**4 & $\mathrm{INCH}^{* * 4}$ & ALUMINUM & \\
\hline 1 & SIMPLE-I & 1.766 & 4.309 & 0.037 & 0.156 & $6061-\mathrm{T} 6$ & 1 \\
\hline 2 & SIMPLE-T & 1.711 & 0.673 & 0.476 & 0.031 & $6061 . \mathrm{T} 6$ & 2 \\
\hline 3 & SIMPI E-Ia & 2.156 & 8.728 & 0.182 & 0.058 & $6061-\mathrm{T} 6$ & 4 \\
\hline 4 & $T$ and $\overline{A R}$ & 1.836 & 0.673 & 0.486 & 0.031 & $6061-\mathrm{T} 6$ & 5 \\
\hline 5 & HALF- $\Gamma$ & 1.398 & 0.662 & 0.203 & 0.023 & $6061-\mathrm{T} 6$ & 7 \\
\hline 6 & HALF-T-BAR & 1.523 & 0.662 & 0.214 & 0.023 & $6061-\mathrm{T} 6$ & 10 \\
\hline 7 & HALF-T-L & 1.628 & 0.682 & 0.224 & 0.024 & $6061-\mathrm{T} 6$ & 11 \\
\hline 8 & 2HALF-T-L-B & 3.152 & 1.344 & 0.438 & 0.047 & $6061-\mathrm{T} 6$ & 12 \\
\hline 9 & $2-\mathrm{L}-1 \mathrm{X} 1$ & 0.460 & 0.042 & 0.042 & 0.003 & $6061-T 6$ & 13 \\
\hline 10 & BAR & 1.406 & 0.046 & 0.593 & 0.150 & $6061-T 6$ & 14 \\
\hline 11 & 2-BAR & 2.813 & 0.092 & 1.186 & 0.301 & $6061-T 6$ & 14 \\
\hline 12 & $L-6 \times 4-1 \times y$ & 4.740 & 16.950 & 6.010 & 0.420 & $6061-T 6$ & 15 \\
\hline 13 & 2-1-BAR & 4.469 & 4.522 & 4.376 & 0.138 & $6061-\mathrm{T} 6$ & 16 \\
\hline 14 & 2-I-BAR-L & 7.319 & 11.672 & 6.306 & 0.279 & $6061-T 6$ & 17 \\
\hline 15 & HALF-Ia & 1.883 & 6.887 & 0.089 & 0.047 & $6061-\mathrm{T} 6$ & 18 \\
\hline 16 & 2-HALF-Ia & 3.766 & 13.773 & 0.179 & 0.094 & $6061-\mathrm{T} 6$ & 20 \\
\hline 17 & SIMPLE-I-B & 2.703 & 4.485 & 0.068 & 0.246 & $6061-T 6$ & 21 \\
\hline 18 & NOZZLETOP & 15.156 & 19.030 & 53.578 & 4.946 & $6061-\mathrm{T} 6$ & 22 \\
\hline 19 & NOZZAE-BTM & 10.000 & 1.302 & 53.333 & 4.639 & $6061-T 6$ & 24 \\
\hline 20 & HALF-Ia-BAR & 11.883 & 1.391 & 60.220 & 4.686 & $6061-\mathrm{T} 6$ & 25 \\
\hline 21 & DOOR-FRAME & 6.313 & 0.775 & 8.080 & 2.383 & $6061-T 6$ & 26 \\
\hline 22 & 2-L-6X4 BOX & 9.480 & 33.900 & 12.020 & 0.840 & $6061-\mathrm{T} 6$ & 15 \\
\hline 23 & 2-L-DOOR-FR & 16.793 & 34.680 & 21.433 & 3.244 & $6061-\mathrm{T} 6$ & 29 \\
\hline 24 & DR-FR-BOTTM & 13.631 & 12.447 & 14.386 & 2.662 & $6061-T 6$ & 31 \\
\hline 25 & DR-FR-TOP & 8.078 & 0.812 & 12.389 & 2.540 & $6061-T 6$ & 32 \\
\hline 26 & L-6X4-PLT-IXy & 5.740 & 16.955 & 7.343 & 0.441 & $6061-\mathrm{T} 6$ & 36 \\
\hline 27 & 2-L-BOX-PL & 10.480 & 33.905 & 13.353 & 0.861 & $6061 \cdot T 6$ & 37 \\
\hline 28 & 2-SIMPLE-I & 3.531 & 8.618 & 0.074 & 0.313 & $6061-\mathrm{T} 6$ & 38 \\
\hline 29 & DR-FR-BTT-R & 10.781 & 5.297 & 12.456 & 3.271 & $6061-\mathrm{T} 6$ & 39 \\
\hline 30 & NOZZIL RIB & 3.438 & 8.665 & 0.112 & 0.412 & $6061-\mathrm{T} 6$ & 40 \\
\hline 31 & DR-FR-Half T & 7.711 & 0.978 & 8.741 & 2.406 & 6061-T6 & 28 \\
\hline 32 & 2-I-BAR-RT14 & 7.319 & 6.306 & 11.672 & 0.279 & $6061-\mathrm{T} 6$ & 17 \\
\hline 33 & DOOR-FR-RT21 & 6.313 & 8.080 & 0.775 & 2.383 & 6061-T6 & 26 \\
\hline 34 & 2-L-DR-FR-RT23 & 16.793 & 21.433 & 34.680 & 3.244 & $6061-\mathrm{T} 6$ & 29 \\
\hline 35 & DR-FR-BT-RT24 & 13.631 & 14.386 & 12.447 & 2.662 & $6061-\mathrm{T} 6$ & 31 \\
\hline 36 & DR-FR-TP-RT25 & 8.078 & 12.389 & 0.812 & 2.540 & $6061-\mathrm{T} 6$ & 32 \\
\hline 37 & DR-FR-TP-RT31 & 7.711 & 8.741 & 0.978 & 2.406 & 6061-T6 & 28 \\
\hline 38 & $B A R-4^{\prime \prime} \times 1^{n}$ & 4.000 & 5.333 & 0.333 & 1.124 & $6061-\mathrm{T} 6$ & 46 \\
\hline 39 & SIMPLE-I-BAR & 4.766 & 4.371 & 9.037 & 0.406 & $6061-T 6$ & 47 \\
\hline 40 & BAR-6"X0.5n & 3.000 & 0.063 & 9.000 & 0.250 & $6061-T 6$ & 47 \\
\hline 41 & L-6X4-P-R26-Ixy & 5.740 & 7.343 & 16.955 & 0.441 & $6061-\mathrm{T} 6$ & 36 \\
\hline 42 & DR-FR-BTT-R-Y & 10.781 & 12.456 & 5.279 & 2.521 & $6061 \cdot \mathrm{T6}$ & 49 \\
\hline 43 & 2-I-BAR-RT 13 & 4.469 & 4.376 & 4.522 & 0.138 & 6061-T6 & 16 \\
\hline 44 & SIMPLE-Ia-RT3 & 2.156 & 0.182 & 8.728 & 0.056 & 6061-T6 & 4 \\
\hline 45 & SIMPLE-Ia-PLT & 3.641 & 4.543 & 8.736 & 0.089 & $6061-T_{6}$ & 50 \\
\hline
\end{tabular}


Table 1

SECTIONAL PROPERTIES

\begin{tabular}{|c|c|c|c|c|c|c|c|}
\hline & & & & & & & \\
\hline MEMBER & SHAPE & AREA & IXx & Iyy & $\mathrm{J}$ & MATERIAL & PAGE \\
\hline NUMBER & & $\mathrm{INCH}^{* * 2}$ & $\mathrm{INCH}^{* * 4}$ & $\mathrm{INCH}^{* * 4}$ & $\mathrm{INCH}^{* * 4}$ & ALUMINUM & \\
\hline 46 & 2-HALF-Ia-RT 16 & 3.766 & 0.179 & 13.773 & 0.094 & $6061-\mathrm{T} 6$ & 20 \\
\hline 47 & 2-SIMPLE-Ia & 4.313 & 8.911 & 8.911 & 0.115 & $6061-\mathrm{T} 6$ & 51 \\
\hline 48 & T-PLATE & 2.789 & 2.344 & 0.482 & 0.053 & $6061 . \mathrm{T} 6$ & 52 \\
\hline 49 & T-DEEP-PLATE & 1.897 & 0.486 & 0.673 & 0.031 & $6061 . \mathrm{T} 6$ & 53 \\
\hline 50 & RACK-BAR & 0.625 & 0.020 & 0.052 & 0.050 & $6061-\mathrm{T} 6$ & 55 \\
\hline 51 & 2-RACK-BARS & 1.250 & 0.041 & 0.104 & 0.099 & $6061-\mathrm{T} 6$ & 55 \\
\hline 52 & 2-HALF-T & 3.152 & 0.438 & 1.344 & 0.047 & $6061-\mathrm{T} 6$ & 56 \\
\hline 53 & SIMPLE-T-RT2 & 1.711 & 0.476 & 0.673 & 0.031 & $6061 . \mathrm{T} 6$ & 2 \\
\hline 54 & WF-5" & 5.672 & 23.813 & 7.832 & 0.266 & $6061-\mathrm{T} 6$ & 78 \\
\hline 55 & WF-8" & 9.281 & 115.188 & 33.558 & 0.435 & $6061-\mathrm{T} 6$ & 79 \\
\hline 56 & PLENUM BAR & 4.000 & 5.333 & 0.333 & 1.124 & $3003-\mathrm{H}-16$ & 84 \\
\hline 57 & MOD-T \& RKBAR & 3.297 & 4.236 & 0.913 & 0.175 & $6061 . \mathrm{T} 6$ & 88 \\
\hline 58 & NOZZLE-BEAM & 44.768 & 18181.630 & 18181.630 & 36363.260 & $3003-H 112$ & 89 \\
\hline & $\mathrm{Ixy}=5.769 \mathrm{in} * * 4$ & & & & & & \\
\hline
\end{tabular}




\begin{tabular}{|c|c|c|c|c|c|c|}
\hline & $\bar{A}$ & $\mathbf{B}$ & C & $\bar{D}$ & $\mathbf{E}$ & $F$ \\
\hline 1 & \multicolumn{6}{|c|}{ PRELIMINARY SPECTRA FOR FILTER COMPARTMENT } \\
\hline 2 & & & & & & \\
\hline$\overline{3}$ & POINT & FREQUENCY & VERTICAL & EAST-WEST & NORTH-SOUTH & $E \cdot W \& N-S$ \\
\hline 4 & & HEATZ & G & $\mathrm{G}$ & $\mathrm{G}$ & $\mathrm{G}$ \\
\hline 5 & & & & & & \\
\hline 6 & 1 & 0.50 & 0.37 & 0.55 & 0.60 & 0.60 \\
\hline 7 & 2 & 0.55 & 0.60 & 0.73 & 0.80 & 0.80 \\
\hline 8 & 3 & 0.70 & 0.60 & 0.73 & 0.80 & 0.80 \\
\hline 9 & 4 & 0.80 & 0.85 & 1.20 & 1.13 & 1.20 \\
\hline 10 & 5 & 1.00 & 0.87 & 1.25 & 1.14 & 1.25 \\
\hline 11 & 6 & 1.20 & 1.05 & 1.28 & 1.45 & 1.45 \\
\hline 12 & 7 & 1.40 & 1.07 & 1.30 & 2.00 & 2.00 \\
\hline 13 & 8 & 1.60 & 1.30 & 2.25 & 2.48 & 2.48 \\
\hline 14 & 9 & 1.80 & 1.55 & 2.50 & 3.40 & 3.40 \\
\hline 15 & 10 & 2.00 & 1.78 & 3.00 & 4.58 & 4.58 \\
\hline 16 & 11 & 2.20 & 2.40 & 3.35 & 4.58 & 4.58 \\
\hline 17 & 12 & 2.40 & 2.40 & 3.55 & 4.58 & 4.58 \\
\hline 18 & 13 & 2.60 & 2.40 & 3.55 & 4.58 & 4.58 \\
\hline 19 & 14 & 2.80 & 2.48 & 3.55 & 4.58 & 4.58 \\
\hline 20 & 15 & 3.40 & 2.48 & 3.55 & 4.58 & 4.58 \\
\hline 21 & 16 & 3.60 & 2.48 & 5.25 & 4.18 & 5.25 \\
\hline 22 & 17 & 3.80 & 2.78 & 6.40 & 3.50 & 6.40 \\
\hline 23 & 18 & 4.00 & 3.28 & 6.40 & 3.13 & 6.40 \\
\hline 24 & 19 & 4.20 & 3.28 & 6.40 & 2.70 & 6.40 \\
\hline 25 & 20 & 4.40 & 3.28 & 6.40 & 2.22 & 6.40 \\
\hline 26 & 21 & 4.60 & 3.28 & 6.40 & 1.88 & 6.40 \\
\hline 27 & 22 & 4.80 & 3.28 & 6.40 & 1.71 & 6.40 \\
\hline 28 & 23 & 5.00 & 3.28 & 6.40 & 1.71 & 6.40 \\
\hline 29 & 24 & 5.20 & 3.28 & 6.40 & 1.71 & 6.40 \\
\hline 30 & 25 & 5.40 & 3.28 & 6.40 & 1.64 & 6.40 \\
\hline 31 & 26 & 6.00 & 3.28 & 6.40 & 1.64 & 6.40 \\
\hline 32 & 27 & 6.20 & 3.28 & 5.00 & 1.64 & 5.00 \\
\hline 33 & 28 & 6.40 & 3.28 & 3.00 & 1.64 & 3.00 \\
\hline 34 & 29 & 5.60 & 3.28 & 2.30 & 1.64 & 2.30 \\
\hline 35 & 30 & 6.80 & 3.28 & 1.80 & 1.64 & 1.80 \\
\hline 36 & 31 & 7.00 & 3.28 & 1.66 & 1.60 & 1.66 \\
\hline 37 & 32 & 7.20 & 3.28 & 1.65 & 1.60 & 1.65 \\
\hline 38 & 33 & 7.40 & 3.72 & 1.66 & 1.50 & 1.66 \\
\hline 39 & 34 & 7.60 & 3.72 & 1.70 & 1.44 & 1.70 \\
\hline 40 & 35 & 7.80 & 3.72 & 1.72 & 1.41 & 1.72 \\
\hline 41 & 36 & 8.00 & 4.00 & 1.74 & 1.41 & 1.74 \\
\hline 42 & 37 & 8.20 & 4.50 & 1.74 & 1.41 & 1.74 \\
\hline 43 & 38 & 8.40 & 5.35 & 1.74 & 1.41 & 1.74 \\
\hline 44 & 39 & 10.40 & 5.35 & 1.74 & 1.41 & 1.74 \\
\hline 45 & 40 & 10.60 & 5.35 & 1.74 & 1.39 & 1.74 \\
\hline 46 & 41 & 10.80 & 5.35 & 1.74 & 1.37 & 1.74 \\
\hline 47 & 42 & 12.40 & 5.35 & 1.74 & 1.37 & 1.74 \\
\hline
\end{tabular}


Table 2 SPECTRA

\begin{tabular}{|c|c|c|c|c|c|c|}
\hline & A & $\mathbf{B}$ & C & $\mathbf{D}$ & $E$ & $F$ \\
\hline 48 & 43 & 12.60 & 4.60 & 1.74 & 1.27 & 1.74 \\
\hline 49 & 44 & 12.80 & 3.50 & 1.10 & 1.13 & 1.13 \\
\hline 50 & 45 & 13.00 & 3.00 & 1.10 & 1.13 & 1.13 \\
\hline 51 & 46 & 13.40 & 3.00 & 1.10 & 1.13 & 1.13 \\
\hline 52 & 47 & 13.60 & 2.68 & 1.10 & 1.13 & 1.13 \\
\hline 53 & 48 & 13.80 & 2.24 & 1.00 & 1.13 & 1.13 \\
\hline 54 & 49 & 14.00 & 2.16 & 1.00 & 1.13 & 1.13 \\
\hline 55 & 50 & 14.20 & 2.08 & 1.00 & 1.13 & 1.13 \\
\hline 56 & 51 & 14.40 & 2.00 & 1.00 & 1.13 & 1.13 \\
\hline 57 & 52 & 14.60 & 1.98 & 1.00 & 1.13 & 1.13 \\
\hline 58 & 53 & 14.80 & 1.95 & 1.00 & 1.13 & 1.13 \\
\hline 59 & 54 & 15.00 & 1.93 & 1.00 & 1.13 & 1.13 \\
\hline 60 & 55 & 15.20 & 1.80 & 1.00 & 1.13 & 1.13 \\
\hline 61 & 56 & 15.40 & 1.73 & 1.00 & 1.13 & 1.13 \\
\hline 62 & 57 & 15.60 & 1.66 & 1.00 & 1.13 & 1.13 \\
\hline 63 & 58 & 15.80 & 1.58 & 1.00 & 1.13 & 1.13 \\
\hline 84 & 59 & 16.00 & 1.55 & 1.00 & 1.13 & 1.13 \\
\hline 65 & 60 & 16.20 & 1.50 & 1.00 & 1.13 & 1.13 \\
\hline 68 & 61 & 16.40 & 1.43 & 1.00 & 1.13 & 1.13 \\
\hline 67 & 62 & 16.60 & 1.40 & 1.00 & 1.13 & 1.13 \\
\hline 68 & 63 & 16.80 & 1.38 & 1.00 & 1.13 & 1.13 \\
\hline 69 & 64 & 17.00 & 1.36 & 1.00 & 1.13 & 1.13 \\
\hline 70 & 65 & 17.20 & 1.34 & 1.00 & 1.13 & 1.13 \\
\hline 71 & 66 & 17.40 & 1.32 & 1.00 & 1.13 & 1.13 \\
\hline 72 & 67 & 17.60 & 1.30 & 1.00 & 1.13 & 1.13 \\
\hline 73 & 68 & 17.80 & 1.28 & 1.00 & 1.13 & 1.13 \\
\hline 74 & 69 & 20.00 & 1.28 & 1.00 & 1.13 & 1.13 \\
\hline 75 & 70 & 21.80 & 0.93 & 0.88 & 0.92 & 0.92 \\
\hline 78 & 71 & 25.00 & 0.93 & 0.88 & 0.92 & 0.92 \\
\hline 77 & 72 & 28.00 & 0.87 & 0.86 & 0.90 & 0.90 \\
\hline 78 & 73 & 31.00 & 0.87 & 0.86 & 0.90 & 0.90 \\
\hline 79 & 74 & 33.00 & 0.81 & 0.84 & 0.88 & 0.88 \\
\hline 80 & 75 & 34.00 & 0.77 & 0.83 & 0.86 & 0.86 \\
\hline
\end{tabular}


Table 3

\begin{tabular}{|c|c|c|c|c|c|c|c|c|}
\hline \multicolumn{9}{|c|}{ FOUR CORNER POINTS OF CROSS SECTIONS } \\
\hline MEMRER & $x(1)$ & $Y(1)$ & $x(2)$ & $Y(2)$ & $x(3)$ & Y/D) & $x(1)$ & \\
\hline \multicolumn{9}{|l|}{ NUMBER } \\
\hline 1 & 0.313 & 2.313 & 0.313 & -2.313 & -0.313 & 2.313 & -0.313 & -2.313 \\
\hline 2 & 1.125 & 1.687 & 1.125 & -1.687 & .1 .125 & 1.687 & -1.125 & -1.687 \\
\hline 3 & 0.750 & 2.750 & 0.750 & -2.750 & -0.750 & 2.750 & -0.750 & -2.750 \\
\hline 4 & 1.125 & 1.812 & 1.125 & -1.812 & -1.125 & 1.812 & -1.125 & -1.812 \\
\hline 5 & 1.125 & 1.687 & 1.125 & -1.687 & -1.125 & 1.687 & -1.125 & -1.687 \\
\hline 6 & 1.125 & 1.812 & 1.125 & -1.812 & -1.125 & 1.812 & -1.125 & -1.812 \\
\hline 7 & 1.125 & 2.687 & 1.125 & -2.687 & -1.125 & 2.687 & -1.125 & -2.687 \\
\hline 8 & 1.438 & 2.687 & 1.438 & -2.687 & -1.438 & 2.687 & -1.438 & -2.687 \\
\hline 9 & 1.000 & 1.000 & 1.000 & -1.000 & -1.000 & 1.000 & -1.000 & -1.000 \\
\hline 10 & 1.125 & 0.313 & 1.125 & -0.313 & -1.125 & 0.313 & -1.125 & -0.313 \\
\hline 11 & 1.125 & 0.625 & 1.125 & -0.625 & -1.125 & 0.625 & -1.125 & -0.625 \\
\hline 12 & 3.030 & 4.040 & 3.030 & -4.040 & -3.030 & 4.040 & 030 & -4.040 \\
\hline 13 & 4.000 & 6.000 & 4.000 & -6.000 & -4.000 & 6.000 & -4.000 & -6.000 \\
\hline 14 & 4.000 & 6.000 & 4.000 & -6.000 & -4.000 & 6.000 & -4.000 & -6.000 \\
\hline 15 & 0.750 & 2.750 & 0.750 & -2.750 & -0.750 & 2.750 & -0.750 & -2.750 \\
\hline 16 & 1.063 & 2.750 & 1.063 & -2.750 & .1 .063 & 2.750 & -1.063 & -2.750 \\
\hline 17 & 0.313 & 3.813 & 0.313 & -3.813 & -0.313 & 3.813 & -0.313 & -3.813 \\
\hline 18 & 4.000 & 6.000 & 4.000 & -6.000 & -4.000 & 6.000 & -4.000 & -6.000 \\
\hline 19 & 4.000 & 0.625 & 4.000 & .0 .625 & -4.000 & 0.625 & -4.000 & -0.625 \\
\hline 20 & 4.000 & 1.542 & 4.000 & -1.542 & -4.000 & 1.542 & -4.000 & -1.542 \\
\hline 21 & 2.125 & 1.500 & 2.125 & -1.500 & -2.125 & $1: 500$ & -2.125 & -1.500 \\
\hline 22 & 3.030 & 4.040 & 3.030 & -4.040 & -3.030 & 4.040 & -3.030 & -4.040 \\
\hline 23 & 3.030 & 5.540 & 3.030 & -5.540 & -3.030 & 5.540 & -3.030 & 540 \\
\hline 24 & 2.313 & 5.000 & 2.313 & -5.000 & -2.313 & 5.0 & -2.313 & -5.000 \\
\hline 25 & 2.313 & 2.250 & 2.313 & -2.250 & -2.313 & 2.250 & -2.313 & -2.250 \\
\hline 26 & 3.030 & 4.290 & 3.030 & -4.290 & -3.030 & 4.290 & -3.030 & -4.290 \\
\hline 27 & 3.030 & 4.290 & 3.030 & -4.290 & .3 .030 & 4.290 & -3.030 & -4.290 \\
\hline 28 & 0.625 & 2.313 & 0.625 & -2.313 & -0.625 & 2.313 & -0.625 & -2.313 \\
\hline 29 & 3.083 & 7.000 & 3.083 & -7.000 & -3.083 & 5.000 & -3.083 & -5.000 \\
\hline 30 & 0.313 & 2.750 & 0.313 & -2.750 & -0.313 & 2.750 & -0.313 & -2.750 \\
\hline 31 & 2.500 & 2.250 & 2.500 & -2.250 & -2.500 & 2.250 & -2.500 & -2.250 \\
\hline 32 & 6.000 & 4.000 & 6.000 & -4.000 & -6.000 & 4.000 & -6.000 & -4.000 \\
\hline 33 & 1.500 & 2.125 & 1.500 & -2.125 & -1.500 & 2.125 & 500 & -2.125 \\
\hline 34 & 5.540 & & 5.540 & -3.030 & -5.540 & 3.030 & -5.540 & -3.030 \\
\hline 35 & 5.000 & 2.313 & 5.000 & -2.313 & -5.000 & 2.313 & -5.000 & -2.313 \\
\hline 36 & 2.250 & 2.313 & 2.250 & -2.313 & -2.250 & 2.313 & -2.250 & -2.313 \\
\hline 37 & 2.250 & 2.500 & 2.250 & -2.500 & -2.250 & 2.500 & -2.250 & -2.500 \\
\hline 38 & 0.500 & 2.000 & 0.500 & -2.000 & -0.500 & 2.000 & -0.500 & -2.000 \\
\hline 39 & 6.000 & 4.500 & 6.000 & -4.500 & -6.000 & 4.500 & -6.000 & -4.500 \\
\hline 40 & 3.000 & 0.250 & 3.000 & -0.250 & -3.000 & 0.250 & -3.000 & -0.250 \\
\hline 41 & 4.290 & 3.030 & 4.290 & -3.030 & -4.290 & 3.030 & -4.290 & -3.030 \\
\hline 42 & 7.000 & 3.083 & 5.000 & -3.083 & -7.000 & 3.083 & -5.000 & -3.083 \\
\hline 43 & 6.000 & 4.000 & 6.000 & -4.000 & .6 .000 & 4.000 & .6 .000 & -4.000 \\
\hline 44 & 2.750 & 0.750 & 2.750 & -0.750 & -2.750 & 0.750 & -2.750 & -0.750 \\
\hline
\end{tabular}


Table 3

\begin{tabular}{|c|c|c|c|c|c|c|c|c|}
\hline \multicolumn{9}{|c|}{ FOUR CORNER POINTS OF CROSS SECTIONS } \\
\hline MEMBER & $x(1)$ & $Y(1)$ & $x(2)$ & $Y(2)$ & $x(3)$ & $Y(3)$ & $x(4)$ & $Y(4)$ \\
\hline \multicolumn{9}{|l|}{ NUMBER } \\
\hline 45 & 5.500 & 6.000 & 5.500 & .8 .000 & -5.500 & 6.000 & -5.500 & -6.000 \\
\hline 46 & 2.750 & 1.063 & 2.750 & -1.063 & -2.750 & 1.063 & -2.750 & -1.063 \\
\hline 47 & 5.500 & 5.500 & 5.500 & -5.500 & -5.500 & 5.500 & -5.500 & -5.500 \\
\hline 48 & 1.125 & 6.000 & 1.125 & -6.000 & $-1 . \overline{125}$ & 6.000 & .1 .125 & .6 .000 \\
\hline 49 & 2.750 & 3.000 & 2.750 & -3.000 & -2.750 & 3.000 & -2.750 & -3.000 \\
\hline 50 & 0.500 & 0.313 & 0.500 & -0.313 & -0.500 & 0.313 & -0.500 & -0.313 \\
\hline 51 & 0.500 & 0.625 & 0.500 & -0.625 & -0.500 & 0.625 & -0.500 & -0.625 \\
\hline 52 & 3.000 & 1.200 & 3.000 & -1.200 & -3.000 & 1.200 & -3.000 & -1.200 \\
\hline 53 & 1.687 & 1.125 & 1.687 & -1.125 & -1.687 & 1.125 & -1.687 & -1.125 \\
\hline 54 & 2.500 & 2.563 & 2.500 & -2.563 & -2.500 & 2.563 & -2.500 & -2.563 \\
\hline 55 & 4.250 & 4.250 & 4.250 & .4 .250 & -4.250 & 4.250 & -4.250 & -4.250 \\
\hline 56 & 0.500 & 2.000 & 0.500 & -2.000 & -0.500 & 2.000 & -0.500 & -2.000 \\
\hline 57 & 2.375 & 2.563 & 2.375 & -2.563 & -2.375 & 2.563 & -2.375 & -2.563 \\
\hline 58 & 28.625 & 28.625 & 28.625 & .28 .625 & -28.625 & 28.625 & .28 .625 & -28.625 \\
\hline
\end{tabular}


BEAM STRESSES

\begin{tabular}{|c|c|c|c|c|c|c|c|}
\hline & $A$ & B & C & D & $E$ & $\mathbf{F}$ & $\mathbf{G}$ \\
\hline 1 & $P \mid D$ & SHAPE & AREA & Ixx & Iyy & $J$ & $x$ \\
\hline 2 & & & INCH* ${ }^{* * 2}$ & $\mathrm{INCH} * * 4$ & $\mathrm{INCH}^{* * 4}$ & $\mathrm{INCH}^{* * 4}$ & INCHES \\
\hline 3 & 1 & SIMPLE-I & 1.766 & 4.309 & 0.037 & 0.156 & 0.313 \\
\hline 4 & 2 & SIMPLE-T & 1.711 & 0.673 & 0.476 & 0.031 & 1.125 \\
\hline 5 & 3 & SIMPLE-Ia & 2.156 & 8.728 & 0.182 & 0.058 & 0.750 \\
\hline 6 & 9 & $2-L-1 \times 1$ & 0.460 & 0.042 & 0.042 & 0.003 & 1.000 \\
\hline 7 & 11 & $2-B A R$ & 2.813 & 0.092 & 1.186 & 0.301 & 1.125 \\
\hline 8 & 18 & NOZZLETOP & 15.156 & 19.030 & 53.578 & 4.946 & 4.000 \\
\hline 9 & 19 & NOZZIE-BTM & 10.000 & 1.302 & 53.333 & 4.639 & 4.000 \\
\hline 10 & 20 & HALF-Ia-BAR & 11.883 & 1.391 & 60.220 & 4.686 & 4.000 \\
\hline 11 & 28 & 2-SIMPLE-I & 3.531 & 8.618 & 0.074 & 0.313 & 0.625 \\
\hline 12 & 30 & NOZZLERIB & 3.438 & 8.665 & 0.112 & 0.412 & 0.313 \\
\hline 13 & 32 & 2-I-BAR-RT 14 & 7.319 & 6.306 & 11.672 & 0.279 & 6.000 \\
\hline 14 & 33 & DOOR-FR-RT21 & 6.313 & 8.080 & 0.775 & 2.383 & 1.500 \\
\hline 15 & 34 & 2-L-DR-FR-RT23 & 16.793 & 21.433 & 34.680 & 3.244 & 5.540 \\
\hline 16 & 35 & DR-FR-BT-RT24 & 13.631 & 14.386 & 12.447 & 2.662 & 5.000 \\
\hline 17 & 36 & DR-FR-TP-KT25 & 8.078 & 12.389 & 0.812 & 2.540 & 2.250 \\
\hline 18 & 37 & DR-FR-TP-RT31 & 7.711 & 8.741 & 0.978 & 2.406 & 2.250 \\
\hline 19 & 38 & BAR-4"X1" & 4.000 & 5.333 & 0.333 & 1.124 & 0.500 \\
\hline 20 & 39 & SIMPLE-I-BAR & 4.766 & 4.371 & 9.037 & 0.406 & 6.000 \\
\hline 21 & 40 & BAR-6"X0.5" & 3.000 & 0.063 & 9.000 & 0.250 & 3.000 \\
\hline 22 & 41 & L-6X4-P-R26-IXy & 5.740 & 7.343 & 16.955 & 0.441 & 4.290 \\
\hline 23 & 42 & DR-FR-BTT-R-Y & 10.781 & 12.456 & 5.279 & 2.521 & 7.000 \\
\hline 24 & 43 & 2-I-BAR-RT 13 & 4.469 & 4.376 & 4,522 & 0.138 & 6.000 \\
\hline 25 & 44 & SIMPLE-Ia-RT 3 & 2.156 & 0.182 & 8.728 & 0.056 & 2.750 \\
\hline 26 & 45 & SIMPLE-Ia-PLT & 3.641 & 4.543 & 8.736 & 0.089 & 5.500 \\
\hline 27 & 46 & 2-HALF-Ia-RT 16 & 3.766 & 0.179 & 13.773 & 0.094 & 2.750 \\
\hline 28 & 47 & 2-SIMPLE-Ia & 4.313 & 8.911 & 8.911 & 0.115 & 5.500 \\
\hline 29 & 48 & T-PLATE & 2.789 & 2.344 & 0.482 & 0.053 & 1.125 \\
\hline 30 & 49 & T-DEEP-PLATE & 1.897 & 0.486 & 0.673 & 0.031 & 2.750 \\
\hline 31 & 50 & RACK-BAR & 0.625 & 0.020 & 0.052 & 0.050 & 0.500 \\
\hline 32 & 51 & 2-RACK-BARS & 1.250 & 0.041 & 0.104 & 0.099 & 0.500 \\
\hline 33 & 52 & 2-HALF-T & 3.152 & 0.438 & 1.344 & 0.047 & 3.000 \\
\hline 34 & 53 & SIMPLE-T-RT2 & 1.711 & 0.476 & 0.673 & 0.031 & 1.687 \\
\hline 35 & 54 & WF-5" & 5.672 & 23.813 & 7.832 & 0.266 & 2.500 \\
\hline 36 & 55 & WF-8" & 9.281 & 115.188 & 33.558 & 0.435 & 4.250 \\
\hline 37 & 56 & PLENUM BAR & 4.000 & 5.333 & 0.333 & 1.124 & 0.500 \\
\hline 38 & 58 & NOZULEBEAM & 44.768 & 18181.630 & 18181.630 & 36363.260 & 28.625 \\
\hline
\end{tabular}

Table 4 
BEAM STRESSES

\begin{tabular}{|c|c|c|c|c|c|c|c|}
\hline & $H$ & 1 & $J$ & $\mathbf{K}$ & $L$ & $\mathbf{M}$ & $N$ \\
\hline 1 & $Y$ & $\mathbf{R}$ & AXIAL FORCE & SHEAR 2 & SHEAR 1 & MOMENT 1 & MOMENT 2 \\
\hline 2 & INCHES & INCHES & POUNCS & POUNDS & POUNDS & INCH-LBS & INCH-LBS \\
\hline 3 & 2.313 & 2.334 & 735.800 & 117.700 & 64.260 & 1960.000 & 19.570 \\
\hline 4 & 1.687 & 2.028 & 268.000 & 30.150 & 4.061 & 284.300 & 30.780 \\
\hline 5 & 2.750 & 2.850 & 129.400 & 24.430 & 5.216 & 776.300 & 11.300 \\
\hline 6 & 1.000 & 1.414 & 124.600 & 36.920 & 24.490 & 15.160 & 24.810 \\
\hline 7 & 0.625 & 1.287 & 317.600 & 18.110 & 307.000 & 9.943 & 535.800 \\
\hline 8 & 6.000 & 7.211 & 112.100 & 23.380 & 32.930 & 311.700 & 679.300 \\
\hline 9 & 0.625 & 4.049 & 117.900 & 20.120 & 70.640 & 34.270 & 1820.000 \\
\hline 10 & 1.542 & 4.287 & 160.000 & 9.145 & 29.340 & 36.880 & 1004.000 \\
\hline 11 & 2.313 & 2.395 & 326.200 & 92.870 & 32.900 & 1660.000 & 28.420 \\
\hline 12 & 2.750 & 2.768 & 120.600 & 77.350 & 24.450 & 1225.000 & 17.240 \\
\hline 13 & 4.000 & 7.211 & 2032.000 & 130.600 & 215.000 & 577.000 & 491.500 \\
\hline 14 & 2.125 & 2.601 & 635.300 & 56.070 & 28.550 & 572.600 & 73.210 \\
\hline 15 & 3.030 & 6.314 & 2718.000 & 68.820 & 107.600 & 378.500 & 830.500 \\
\hline 16 & 2.313 & 5.509 & 1648.000 & 48.790 & 103.100 & 319.800 & 254.800 \\
\hline 17 & 2.313 & 3.226 & 285.800 & $57.1 \%$ & 45.720 & 1288.000 & 72.520 \\
\hline 18 & 2.500 & 3.363 & 1777.000 & 106.200 & 19.420 & 946.300 & 53.450 \\
\hline 19 & 2.000 & 2.062 & 170.400 & 92.310 & 16.130 & 903.500 & 37.130 \\
\hline 20 & 4.500 & 7.500 & 536.500 & 80.190 & 22.050 & 161.600 & 81.450 \\
\hline 21 & 0.250 & 3.010 & 118.200 & 1.821 & 19.850 & 9.294 & 46.530 \\
\hline 22 & 3.030 & 5.252 & 1957.000 & 93.230 & 205.400 & 438.400 & 756.100 \\
\hline 23 & 3.083 & 7.649 & 2089.000 & 260.100 & 219.800 & 1397.000 & 476.100 \\
\hline 24 & 4.000 & 7.211 & 1514.000 & 94.360 & 185.100 & 433.500 & 393.100 \\
\hline 25 & 0.750 & 2.850 & 225.000 & 10.770 & 18.970 & 20.910 & 1100.000 \\
\hline 26 & 6.000 & 8.139 & 2445.000 & 106.100 & 26.790 & 371.900 & 382.400 \\
\hline 27 & 1.063 & 2.948 & 204.100 & 3.824 & 25.660 & 12.100 & 1331.000 \\
\hline 28 & 5.500 & 7.778 & 10.570 & 7.748 & 13.050 & 61.440 & 91.000 \\
\hline 29 & 6.000 & 6.105 & 326.200 & 64.810 & 8.633 & 928.900 & 30.260 \\
\hline 30 & 3.000 & 4.070 & 236.700 & 25.920 & 7.373 & 56.190 & 254.600 \\
\hline 31 & 0.313 & 0.590 & 190.900 & 2.359 & 18.270 & 2.966 & 19.560 \\
\hline 32 & 0.625 & 0.800 & 156.800 & 0.964 & 17.150 & 2.166 & 8.542 \\
\hline 33 & 1.200 & 3.231 & 162.000 & 14.110 & 173.400 & 8.634 & 223.400 \\
\hline 34 & 1.125 & 2.028 & 204.900 & 39.130 & 56.740 & 44.870 & 227.500 \\
\hline 35 & 2.563 & 3.580 & 597.900 & 307.800 & 56.650 & 3165.000 & 473.300 \\
\hline 36 & 4.250 & 6.010 & 1379.000 & 314.600 & 183.600 & 6850.000 & 939.900 \\
\hline 37 & 2.000 & 2.062 & 96.170 & 11.470 & 17.040 & 466.100 & 38.420 \\
\hline 38 & 28.625 & 40.482 & 0.000 & $2: 1.200$ & 1635.000 & 11670.000 & 70940.000 \\
\hline
\end{tabular}

Table 4 
BEAM STRESSES

\begin{tabular}{|c|c|c|c|c|c|c|}
\hline & 0 & $\mathbf{P}$ & $a$ & $\mathbf{R}$ & $\mathbf{S}$ & $T$ \\
\hline 1 & TORSION & $P / A$ & SHEAR 2/A & SHEAR 1/A & SHEAR $1,2 / A$ & $T^{\circ} R / J$ \\
\hline 2 & INCH-LBS & PSI & PSI & PSI & PSI & PSI \\
\hline 3 & 47.940 & 416.648 & 66.648 & 36.387 & 75.934 & 717.108 \\
\hline 4 & 1.948 & 156.634 & 17.621 & 2.373 & 17.780 & 127.418 \\
\hline 5 & 1.848 & 60.019 & 11.331 & 2.419 & 11.587 & 90.821 \\
\hline 6 & 0.319 & 270.870 & 80.261 & 53.239 & 96.313 & 150.425 \\
\hline 7 & 11.450 & 112.904 & 6.438 & 109.136 & 109.326 & 48.988 \\
\hline 8 & 274.600 & 7.396 & 1.543 & 2.173 & 2.665 & 400.358 \\
\hline 9 & 278.000 & 11.790 & 2.012 & 7.064 & 7.345 & 242.615 \\
\hline 10 & 231.900 & 13.465 & 0.770 & 2.469 & 2.586 & 212.146 \\
\hline 11 & 22.030 & 92.382 & 26.301 & 9.317 & 27.903 & 168.601 \\
\hline 12 & 61.060 & 35.079 & 22.499 & 7.112 & 23.596 & 410.184 \\
\hline 13 & 21.660 & 277.634 & 17.844 & 29.376 & 34.371 & 559.830 \\
\hline 14 & 59.500 & 100.634 & 8.882 & 4.522 & 9.967 & 64.945 \\
\hline 15 & 54.340 & 161.853 & 4.098 & 6.407 & 7.606 & 105.773 \\
\hline 16 & 64.770 & 120.901 & 3.579 & 7.564 & 8.368 & 134.038 \\
\hline 17 & 28.550 & 35.380 & 7.077 & 5.660 & 9.062 & 36.266 \\
\hline 18 & 54.610 & 230.450 & 13.773 & 2.518 & 14.001 & 76.341 \\
\hline 19 & 51.160 & 42.600 & 23.078 & 4.033 & 23.427 & 93.834 \\
\hline 20 & 68.050 & 112.568 & 16.825 & 4.627 & 17.450 & 1257.081 \\
\hline 21 & 13.440 & 39.400 & 0.607 & 6.617 & 6.644 & 161.839 \\
\hline 22 & 158.700 & 340.941 & 16.242 & 35.784 & 29.298 & 1890.057 \\
\hline 23 & 61.490 & 193.767 & 24.126 & 20.388 & 31.587 & 186.567 \\
\hline 24 & 10.690 & 338.778 & 21.114 & 41.419 & 46.490 & 558.599 \\
\hline 25 & 8.489 & 104.360 & 4.995 & 8.799 & $10 . \overline{118}$ & 432.096 \\
\hline 26 & 5.801 & 671.588 & 29.143 & 7.359 & 30.058 & 533.522 \\
\hline 27 & 1.212 & 54.195 & 1.015 & 6.814 & 6.889 & 38.012 \\
\hline 28 & 1.797 & 2.451 & 1.797 & 3.026 & 3.519 & 121.467 \\
\hline 29 & 5.774 & 116.957 & 23.237 & 3.095 & 23.442 & 664.302 \\
\hline 30 & 7.129 & 124.776 & 13.664 & 3.887 & 14.206 & 926.931 \\
\hline 31 & 7.938 & 305.440 & 3.774 & 29.232 & 29.475 & 94.554 \\
\hline 32 & 2.149 & 125.440 & 0.771 & 13.720 & 13.742 & 17.387 \\
\hline 33 & 0.833 & 51.396 & 4.477 & 55.013 & 55.195 & 57.435 \\
\hline 34 & 4.099 & 119.755 & 22.870 & 33.162 & 40.283 & 268.115 \\
\hline 35 & 12.870 & 105.415 & 54.268 & 9.988 & 55.179 & 173.298 \\
\hline 36 & 25.310 & 148.579 & 33.896 & 19.782 & 39.246 & 349.662 \\
\hline 37 & 56.440 & 24.043 & 2.868 & 4.260 & 5.135 & 103.518 \\
\hline 38 & 0.000 & 0.000 & 4.941 & 36.522 & 36.855 & 0.000 \\
\hline
\end{tabular}

Table 4 
BEAM STRESSES

\begin{tabular}{|c|c|c|c|c|c|c|}
\hline & $\mathbf{U}$ & V & $W$ & $x$ & $\mathbf{Y}$ & $\mathbf{z}$ \\
\hline 1 & TOTAL SHEAR & BENDING S1 & BENDING S2 & TOTAL AXIALS & MAX SHEAR & MAX AXIALS \\
\hline 2 & $\mathrm{PSI}$ & PSI & PSI & PSI & PSI & PSI \\
\hline 3 & 793.042 & 1051.868 & 165.287 & 1633.803 & 1138.527 & 1955.429 \\
\hline 4 & 145.199 & 712.651 & 72.747 & 942.031 & 492.888 & 963.904 \\
\hline 5 & 102.407 & 244.595 & 46.566 & 351.179 & 203.271 & 378.861 \\
\hline 6 & 246.738 & 360.952 & 590.714 & 1222.536 & 659.188 & 1270.456 \\
\hline 7 & 158.314 & 67.548 & 508.242 & 688.694 & 378.996 & 723.343 \\
\hline 8 & 403.022 & 98.276 & 50.715 & 156.388 & 410.538 & 488.732 \\
\hline 9 & 249.960 & 16.451 & 136.501 & 164.742 & 263.183 & 345.553 \\
\hline 10 & 214.732 & 40.876 & 66.689 & 121.029 & 223.096 & 283.610 \\
\hline 11 & 196.504 & 445.434 & 240.034 & 777.850 & 435.748 & 824.673 \\
\hline 12 & 433.779 & 388.777 & 48.103 & 471.958 & 493.812 & 729.791 \\
\hline 13 & 594.200 & 366.001 & 252.656 & 896.290 & 744.250 & 1192.395 \\
\hline 14 & 74.912 & 150.591 & 141.697 & 392.921 & 210.258 & 406.719 \\
\hline 15 & 113.379 & 53.509 & 132.669 & 348.031 & 207.693 & 381.708 \\
\hline 16 & 142.406 & 51.407 & 102.354 & 274.662 & 197.836 & 335.167 \\
\hline 17 & 45.328 & 240.415 & 200.948 & 476.743 & 242.643 & 481.015 \\
\hline 18 & 90.342 & 270.650 & 122.968 & 624.068 & 324.849 & 636.883 \\
\hline 19 & 112.261 & 338.813 & 55.696 & 437.108 & 248.024 & 466.578 \\
\hline 20 & 1274.531 & 166.369 & 54.078 & 333.015 & 1285.362 & 1451.869 \\
\hline 21 & 168.483 & 37.176 & 15.510 & 92.086 & 174.662 & 220.705 \\
\hline 22 & 1929.354 & 180.900 & 191.310 & 713.152 & 1962.028 & 2318.604 \\
\hline 23 & 218.154 & 345.811 & 631.313 & 1170.890 & 624.770 & 1210.215 \\
\hline 24 & 605.089 & 396.252 & 521.583 & 1256.614 & 872.297 & 1500.604 \\
\hline 25 & 442.214 & 86.168 & 346.586 & 537.113 & 517.374 & 785.930 \\
\hline 26 & 563.580 & 491.173 & 240.751 & 1403.512 & 900.047 & 1601.803 \\
\hline 27 & 44.901 & 71.823 & 265.755 & 391.774 & 200.967 & 396.854 \\
\hline 28 & 124.986 & 37.924 & 56.170 & 96.544 & 133.984 & 182.256 \\
\hline 29 & 687.744 & 2370.093 & 70.696 & 2565.745 & 1455.594 & 2738.466 \\
\hline 30 & 941.136 & 346.852 & 1040.342 & 1511.970 & 1207.166 & 1963.151 \\
\hline 31 & 124.029 & 45.558 & 187.776 & 538.774 & 296.568 & 565.955 \\
\hline 32 & 31.129 & 33.270 & 41.002 & 199.711 & 104.595 & 204.451 \\
\hline 33 & 112.630 & 23.655 & 498.661 & 573.711 & 308.175 & 595.030 \\
\hline 34 & 308.398 & 106.048 & 570.271 & 796.073 & 503.530 & 901.567 \\
\hline 35 & 228.477 & 340.581 & 151.084 & 597.080 & 375.936 & 674.476 \\
\hline 36 & 388.908 & 252.738 & 119.036 & 520.353 & 467.912 & 728.089 \\
\hline 37 & 108.653 & 174.788 & 57.630 & 256.460 & 168.073 & 296.303 \\
\hline 38 & 36.855 & 18.373 & 111.687 & 130.060 & 74.748 & 139.778 \\
\hline
\end{tabular}

Table 4 
Table 5 BASE REACTION FORCES

\begin{tabular}{|c|c|c|c|c|c|c|c|}
\hline & A & \begin{tabular}{|c|} 
B \\
\end{tabular} & $\mathrm{C}$ & D & $E$ & $\mathbf{F}$ & $G$ \\
\hline 1 & & Modal Dynamic & Modal Dynamic & Static & Difference & Uplift & Downhold \\
\hline 2 & Node & Without ZPA & with ZPA & Dead Weight [ & Dynamic-Static & Force & Force \\
\hline 3 & & Pounds & Pounds & Pounds & Pounds & Pounds & Pounds \\
\hline 4 & 642 & 156.00 & 162.52 & 12.07 & 150.45 & 150.45 & \\
\hline 5 & 644 & 17.85 & 24.86 & 12.98 & 11.88 & 11.88 & \\
\hline 6 & 647 & 2133.00 & 2647.89 & 953.50 & 1694.39 & 1694.39 & \\
\hline 7 & 707 & 18.38 & 20.09 & 3.17 & 16.92 & 16.92 & \\
\hline 8 & 710 & 10.08 & 11.55 & 2.72 & 8.83 & 8.83 & \\
\hline 9 & 714 & 74.51 & 80.10 & 10.36 & 69.74 & 69.74 & \\
\hline 10 & 768 & 12.66 & 14.17 & 2.79 & 11.38 & 11.38 & \\
\hline 11 & 771 & 1.40 & 3.19 & 3.31 & -0.13 & & -0.13 \\
\hline 12 & 774 & 51.52 & 54.47 & 5.46 & 49.01 & 49.01 & \\
\hline 13 & 825 & 32.19 & 51.07 & 34.96 & 16.11 & 16.11 & \\
\hline 14 & 826 & 13.63 & 15.97 & 4.33 & 11.64 & 11.64 & \\
\hline 15 & 829 & 3.89 & 6.37 & 4.58 & 1.79 & 1.79 & \\
\hline 16 & 885 & 661.30 & 885.72 & 415.60 & 470.12 & 470.12 & \\
\hline 17 & 887 & 3.04 & 5.40 & 4.37 & 1.03 & 1.03 & \\
\hline 18 & 890 & 2.46 & 5.29 & 5.23 & 0.06 & 0.06 & \\
\hline 19 & 942 & 100.40 & 113.34 & 23.97 & 89.37 & 89.37 & \\
\hline 20 & 945 & 33.60 & 35.06 & 2.71 & 32.35 & 32.35 & \\
\hline 21 & 948 & 3.51 & 4.72 & 2.24 & 2.48 & 2.48 & \\
\hline 22 & 986 & 1015.00 & 1400.78 & 714.40 & 686.38 & 686.38 & \\
\hline 23 & 1001 & 5.73 & 7.45 & 3.18 & 4.27 & 4.27 & \\
\hline 24 & 1002 & 28.24 & 29.53 & 2.38 & 27.14 & 27.14 & \\
\hline 25 & 1042 & 69.40 & 73.05 & 6.76 & 66.29 & 66.29 & \\
\hline 26 & 1058 & 7.28 & 9.45 & 4.01 & 5.44 & 5.44 & \\
\hline 27 & 1060 & 13.52 & 15.63 & 3.91 & 11.72 & 11.72 & \\
\hline 28 & 1075 & 19.68 & 21.02 & 2.48 & 18.54 & 18.54 & \\
\hline 29 & 1105 & 7.99 & 11.74 & 6.94 & 4.79 & 4.79 & \\
\hline 30 & 1121 & 4.91 & 6.45 & 2.84 & 3.60 & 3.60 & \\
\hline 31 & 1124 & 14.62 & 16.42 & 3.33 & 13.09 & 13.09 & \\
\hline 32 & 1176 & 614.80 & 772.43 & 291.90 & 480.53 & 480.53 & \\
\hline 33 & 1182 & 31.86 & 31.88 & -0.04 & 31.92 & 31.92 & \\
\hline 34 & 1195 & 36.95 & 39.63 & 4.96 & 34.67 & 34.67 & \\
\hline 35 & 1245 & 93.51 & 112.73 & 35.60 & 77.13 & 77.13 & \\
\hline 36 & 1247 & 427.60 & 701.06 & 506.40 & 194.66 & 194.66 & \\
\hline 37 & 1263 & 76.30 & 358.02 & 521.70 & -163.68 & & -163.68 \\
\hline 38 & 1274 & 14.50 & 16.28 & 3.30 & 12.98 & 12.98 & \\
\hline 39 & 1298 & 47.41 & 47.70 & 0.54 & 47.16 & 47.16 & \\
\hline 40 & 1316 & 2459.00 & 2980.86 & 966.40 & 2014.46 & 2014.46 & \\
\hline 41 & 1319 & 419.90 & 744.82 & 601.70 & 143.12 & 143.12 & \\
\hline 42 & 1333 & 69.17 & 411.69 & 634.30 & -222.61 & & -222.61 \\
\hline 43 & 1379 & 74.22 & 97.92 & 43.88 & 54.04 & 54.04 & \\
\hline 44 & 1384 & 29.92 & 33.38 & 6.40 & 26.97 & 26.97 & \\
\hline 45 & 1400 & 63.02 & 67.37 & 8.06 & 59.31 & 59.31 & \\
\hline 46 & 1437 & 10.08 & 15.79 & 10.57 & 5.22 & 5.22 & \\
\hline 47 & 1440 & 6.96 & 8.90 & 3.60 & 5.30 & 5.30 & \\
\hline
\end{tabular}


Table 5 BASE REACTION FORCES

\begin{tabular}{|c|c|c|c|c|c|c|c|}
\hline & A & \begin{tabular}{c|}
$\mathbf{B}$ \\
\end{tabular} & $\mathrm{C}$ & D & $E$ & $\mathbf{F}$ & $\mathbf{G}$ \\
\hline 48 & & Modal Dynamic & Modal Dynamic & Static & Difference & Uplift & Downhold \\
\hline 49 & Node & Without ZPA & with ZPA & Dead Weight D & Dynamic-Static & Force & Force \\
\hline 50 & & Pounds & Pounds & Pounds & Pounds & Pounds & Pounds \\
\hline 51 & 1455 & 12.16 & 13.67 & 2.79 & 10.88 & 10.88 & \\
\hline 52 & 1491 & 6.83 & 13.77 & 12.85 & 0.92 & 0.92 & \\
\hline 53 & 1494 & 2.80 & 4.73 & 3.58 & 1.15 & 1.15 & \\
\hline 54 & 1497 & 4.75 & 6.36 & 2.99 & 3.37 & 3.37 & \\
\hline 55 & 1548 & 10.12 & 26.67 & 30.64 & -3.97 & & -3.97 \\
\hline 56 & 1551 & 3.47 & 5.22 & 3.25 & 1.97 & 1.97 & \\
\hline 57 & 1554 & 2.90 & 4.41 & 2.81 & 1.61 & 1.61 & \\
\hline 58 & 1613 & 508.00 & 727.67 & 406.80 & 320.87 & 320.87 & \\
\hline 59 & 1616 & 3.06 & 4.03 & 1.80 & 2.23 & 2.23 & \\
\hline 60 & 1619 & 4.31 & 5.19 & 1.62 & 3.57 & 3.57 & \\
\hline 61 & 1691 & 98.89 & 108.01 & 16.88 & 91.13 & 91.13 & \\
\hline 62 & 1694 & 0.43 & 1.21 & 1.45 & -0.23 & & -0.23 \\
\hline 63 & 1697 & 4.30 & 5.01 & 1.31 & 3.70 & 3.70 & \\
\hline 64 & 1761 & 672.10 & 1040.38 & 682.00 & 358.38 & 358.38 & \\
\hline 65 & 1764 & 0.27 & 1.16 & 1.65 & -0.49 & & -0.49 \\
\hline 66 & 1767 & 2.89 & 3.78 & 1.66 & 2.12 & 2.12 & \\
\hline 67 & 1784 & 99.66 & 104.98 & 9.86 & 95.13 & 95.13 & \\
\hline 68 & 1846 & 1.74 & 3.12 & 2.55 & 0.57 & 0.57 & \\
\hline 69 & 1849 & 1.02 & 2.43 & 2.60 & -0.17 & & -0.17 \\
\hline 70 & 1863 & 8.70 & 10.03 & 2.47 & 7.56 & 7.56 & \\
\hline 71 & 1941 & 5.93 & 7.62 & 3.14 & 4.48 & 4.48 & \\
\hline 72 & 1944 & 5.90 & 7.21 & 2.42 & 4.79 & 4.79 & \\
\hline 73 & 1958 & 37.06 & 64.09 & 50.05 & 14.04 & 14.04 & \\
\hline 74 & 2052 & 18.72 & 53.22 & 63.89 & -10.67 & & -10.67 \\
\hline 75 & 2055 & 13.06 & 71.76 & 108.70 & -36.94 & & -36.94 \\
\hline 76 & 2068 & 19.59 & 33.45 & 25.67 & 7.78 & 7.78 & \\
\hline 77 & 2071 & 15.53 & 16.71 & 2.18 & 14.53 & 14.53 & \\
\hline 78 & 2139 & 24.08 & 25.39 & 2.42 & 22.97 & 22.97 & \\
\hline 79 & 2155 & 62.69 & 291.54 & 423.80 & -132.26 & & -132.26 \\
\hline 80 & 2156 & 15.04 & 276.13 & 483.50 & -207.37 & & .207 .37 \\
\hline 81 & 2167 & 368.40 & 652.22 & 525.60 & 126.62 & 126.62 & \\
\hline 82 & 2266 & 17.06 & 18.33 & 2.36 & 15.97 & 15.97 & \\
\hline 83 & 2268 & 24.55 & 26.00 & 2.69 & 23.31 & 23.31 & \\
\hline 84 & 2280 & 22.60 & 39.86 & 31.97 & 7.89 & 7.89 & \\
\hline 85 & 2360 & 2.59 & 4.56 & 3.64 & 0.92 & 0.92 & \\
\hline 86 & 2364 & 5.96 & 7.85 & 3.49 & 4.36 & 4.36 & \\
\hline 87 & 2373 & 1.56 & 7.50 & 11.00 & 3.50 & & -3.50 \\
\hline 88 & 2449 & 2.32 & 4.25 & 3.58 & u. 57 & 0.67 & \\
\hline 89 & 2452 & 2.44 & 4.19 & 3.24 & 0.95 & 0.95 & \\
\hline 90 & 2454 & 19.87 & 27.29 & 13.74 & 13.55 & 13.55 & \\
\hline 91 & 2528 & 4.53 & 6.17 & 3.04 & 3.13 & 3.13 & \\
\hline 92 & 2530 & 0.94 & 2.40 & 2.71 & -0.31 & & -0.31 \\
\hline 93 & 2532 & 6.77 & 22.34 & 28.83 & -6.49 & & -6.49 \\
\hline 94 & 2611 & 0.81 & 1.75 & 1.75 & 0.00 & 0.00 & \\
\hline
\end{tabular}


Table 5 BASE REACTION FORCES

\begin{tabular}{|c|c|c|c|c|c|c|c|}
\hline & A & B & $\mathrm{C}$ & $D$ & $E$ & $F$ & $\mathrm{G}$ \\
\hline 95 & & Modal Dynamic & Modal Dynamic & Static & Difference & Uplift & Downhold \\
\hline 96 & Node & Without ZPA & with $Z P A$ & Dead Weight & Dynamic-Static & Force & Force \\
\hline 97 & & Pounds & Pounds & Pounds & Pounds & Pounds & Pounds \\
\hline 98 & 2614 & 1.04 & 1.95 & 1.68 & 0.27 & 0.27 & \\
\hline 99 & 2616 & 326.70 & 534.71 & 385.20 & 149.51 & 149.51 & \\
\hline 100 & 2674 & 1.65 & 2.54 & 1.66 & 0.88 & 0.88 & \\
\hline 101 & 2677 & 0.79 & 1.53 & 1.36 & 0.16 & 0.16 & \\
\hline 102 & 2679 & 183.30 & 192.00 & 16.11 & 175.89 & 175.89 & \\
\hline 103 & 2724 & 0.88 & 1.76 & 1.63 & 0.13 & 0.13 & \\
\hline 104 & 2727 & 0.68 & 1.55 & 1.60 & -0.05 & & -0.05 \\
\hline 105 & 2729 & 639.00 & 1007.50 & 682.40 & 325.10 & 325.10 & \\
\hline 106 & 2750 & 192.10 & 196.98 & 9.03 & 187.95 & 187.95 & \\
\hline 107 & 2776 & 2.10 & 3.47 & 2.54 & 0.93 & 0.93 & \\
\hline 108 & 2778 & 1.04 & 2.40 & 2.52 & -0.12 & & -0.12 \\
\hline 109 & 2799 & 17.50 & 18.59 & 2.03 & 16.57 & 16.57 & \\
\hline 110 & 2831 & 2.87 & 4.28 & 2.61 & 1.67 & 1.67 & \\
\hline 111 & 2833 & 1.03 & 2.28 & 2.31 & -0.03 & & -0.03 \\
\hline 112 & 2842 & 75.41 & 103.75 & 52.48 & 51.27 & 51.27 & \\
\hline 113 & 2881 & 3.52 & 26.76 & 43.04 & -16.28 & & -16.28 \\
\hline 114 & 2882 & 8.60 & 42.57 & 62.91 & -20.34 & & -20.34 \\
\hline 115 & 2890 & 76.01 & 90.10 & 26.10 & 64.00 & 64.00 & \\
\hline 116 & 2903 & 18.44 & 19.49 & 1.94 & 17.55 & 17.55 & \\
\hline 117 & 2923 & 17.61 & 18.71 & 2.04 & 16.67 & 16.67 & \\
\hline 118 & 2932 & 102.00 & 230.95 & 238.80 & -7.85 & & -7.85 \\
\hline 119 & 2933 & 70.01 & 187.03 & 216.70 & -29.67 & & -29.67 \\
\hline 120 & 2940 & 640.20 & 767.26 & 235.30 & 531.96 & 531.96 & \\
\hline 121 & 2974 & 54.95 & 56.88 & 3.58 & 53.31 & 53.31 & \\
\hline 122 & 2977 & 9.39 & 11.59 & 4.07 & 7.52 & 7.52 & \\
\hline 123 & 2985 & 63.63 & 78.84 & 28.17 & 50.67 & 50.67 & \\
\hline 124 & 3009 & 16.46 & 19.04 & 4.78 & 14.26 & 14.26 & \\
\hline 125 & 3013 & 7.18 & 9.36 & 4.04 & 5.32 & 5.32 & \\
\hline 126 & 3018 & 206.50 & 211.14 & 8.60 & 202.54 & 202.54 & \\
\hline 127 & 3043 & 25.09 & 27.36 & 4.20 & 23.16 & 23.16 & \\
\hline 128 & 3045 & 23.72 & 26.08 & 4.36 & 21.71 & 21.71 & \\
\hline 129 & 3047 & 1206.00 & 1623.47 & 773.10 & 850.37 & 850.37 & \\
\hline 130 & 3060 & 0.40 & 9.80 & 17.41 & -7.61 & & -7.61 \\
\hline 131 & 3073 & 0.03 & 5.15 & 9.49 & -4.34 & & -4.34 \\
\hline 132 & 3076 & 12.38 & 14.59 & 4.09 & 10.50 & 10.50 & \\
\hline 133 & 3089 & 181.50 & 194.92 & 24.86 & 170.06 & 170.06 & \\
\hline 134 & 3102 & 19.30 & 21.31 & 3.72 & 17.59 & 17.59 & \\
\hline 135 & 3105 & 22.13 & 24.01 & 3.49 & 20.53 & 20.53 & \\
\hline 136 & 3117 & 2440.00 & 2756.44 & 586.00 & 2170.44 & 2170.44 & \\
\hline 137 & 3133 & 84.91 & 92.84 & 14.69 & 78.15 & 78.15 & \\
\hline 138 & 3134 & 195.90 & 202.65 & 12.50 & 190.15 & 190.15 & \\
\hline 139 & 3852 & 88.50 & 97.10 & 15.93 & 81.17 & 81.17 & \\
\hline 140 & 3855 & 3221.00 & 3758.35 & 995.10 & 2763.25 & 2763.25 & \\
\hline 141 & 3915 & 12.32 & 14.10 & 3.30 & 10.80 & 10.80 & \\
\hline
\end{tabular}




\begin{tabular}{|c|c|c|c|c|c|c|c|}
\hline & A & B & $\mathrm{C}$ & D & $E$ & $\mathbf{F}$ & $\mathbf{G}$ \\
\hline 142 & & Modal Dynamic & Modal Dynamic & Static & Difference & Uplift & Downhold \\
\hline 143 & Node & Without ZPA & with ZPA & Dead Weight [ & Dynamic-static & Force & Force \\
\hline 144 & & Pounds & Pounds & Pounds & Pounds & Pounds & Pounds \\
\hline 145 & 3919 & 264.80 & 272.04 & 13.40 & 258.64 & 258.64 & \\
\hline 146 & 3973 & 48.62 & 49.89 & 2.35 & 47.54 & 47.54 & \\
\hline 147 & 3976 & 133.10 & 139.07 & 11.06 & 128.01 & 128.01 & \\
\hline 148 & 4025 & 0.13 & 18.61 & 34.23 & -15.62 & & -15.62 \\
\hline 149 & 4028 & 0.60 & 6.21 & 10.39 & -4.18 & & -4.18 \\
\hline 150 & 4082 & 380.40 & 601.37 & 409.20 & 192.17 & 192.17 & \\
\hline 151 & 4086 & 59.18 & 61.46 & 4.21 & 57.24 & 57.24 & \\
\hline 152 & 4136 & 188.10 & 200.21 & 22.42 & 177.79 & 177.79 & \\
\hline 153 & 4141 & 28.82 & 30.18 & 2.52 & 27.66 & 27.66 & \\
\hline 154 & 4177 & 871.60 & 1250.57 & 701.80 & 548.77 & 548.77 & \\
\hline 155 & 4192 & 12.07 & 13.83 & 3.26 & 10.57 & 10.57 & \\
\hline 156 & 4229 & 153.30 & 155.43 & 3.95 & 151.48 & 151.48 & \\
\hline 157 & 4245 & 20.21 & 22.18 & 3.65 & 18.53 & 18.53 & \\
\hline 158 & 4260 & 12.41 & 12.58 & 0.31 & 12.27 & 12.27 & \\
\hline 159 & 4284 & 3.02 & 6.15 & 5.79 & 0.36 & 0.36 & \\
\hline 160 & 4300 & 5.73 & 7.44 & 3.16 & 4.28 & 4.28 & \\
\hline 161 & 4344 & 736.10 & 891.94 & 288.60 & 603.34 & 603.34 & \\
\hline 162 & 4350 & 55.53 & 55.80 & -0.49 & 56.29 & 56.29 & \\
\hline 163 & 4408 & 120.70 & 139.35 & 34.53 & 104.82 & 104.82 & \\
\hline 164 & 4410 & 377.90 & 650.76 & 505.30 & 145.46 & 145.46 & \\
\hline 165 & 4435 & 32.90 & 34.59 & 3.12 & 31.46 & 31.46 & \\
\hline 166 & 4474 & 2511.00 & 3029.40 & 960.00 & 2069.40 & 2069.40 & \\
\hline 167 & 4477 & 377.40 & 701.45 & 600.10 & 101.35 & 101.35 & \\
\hline 168 & 4534 & 78.83 & 101.41 & 41.82 & 59.59 & 59.59 & \\
\hline 169 & 4539 & 29.92 & 33.36 & 6.37 & 26.99 & 26.99 & \\
\hline 170 & 4589 & 21.79 & 26.36 & 8.46 & 17.90 & 17.90 & \\
\hline 171 & 4592 & 6.20 & 8.14 & 3.59 & 4.55 & 4.55 & \\
\hline 172 & 4640 & 4.68 & 10.56 & 10.88 & -0.32 & & -0.32 \\
\hline 173 & 4643 & 3.98 & 5.91 & 3.58 & 2.33 & 2.33 & \\
\hline 174 & 4692 & 28.58 & 44.26 & 29.04 & 15.22 & 15.22 & \\
\hline 175 & 4695 & 4.98 & 6.69 & 3.18 & 3.51 & 3.51 & \\
\hline 176 & 4752 & 486.40 & 704.40 & 403.70 & 300.70 & 300.70 & \\
\hline 177 & 4755 & 2.60 & 3.55 & 1.75 & 1.80 & 1.80 & \\
\hline 178 & 4816 & 107.40 & 116.27 & 16.42 & 99.85 & 99.85 & \\
\hline 179 & 4819 & 1.23 & 2.11 & 1.64 & 0.47 & 0.47 & \\
\hline 180 & 4882 & 641.70 & 1007.87 & 678.10 & 329.77 & 329.77 & \\
\hline 181 & 4885 & 1.17 & 2.17 & 1.85 & 0.32 & 0.32 & \\
\hline 182 & 4904 & 119.50 & 123.80 & 7.97 & 115.83 & 115.83 & \\
\hline 183 & 4957 & 1.23 & 2.43 & 2.23 & 0.20 & 0.20 & \\
\hline 184 & 4973 & 16.16 & 16.64 & 0.89 & 15.75 & 15.75 & \\
\hline 185 & 5038 & 6.01 & 7.60 & 2.94 & 4.66 & 4.66 & \\
\hline 186 & 5054 & 36.22 & 62.57 & 48.80 & 13.77 & 13.77 & \\
\hline 187 & 5138 & 17.75 & 52.37 & 64.11 & -11.74 & & -11.74 \\
\hline 188 & 5153 & 17.91 & 30.93 & 24.11 & 6.82 & 6.82 & \\
\hline
\end{tabular}


Table 5 BASE REACTION FORCES

\begin{tabular}{|c|c|c|c|c|c|c|c|}
\hline & $A$ & B & $\mathrm{C}$ & D & $\mathrm{E}$ & $\mathbf{F}$ & $\mathbf{G}$ \\
\hline 189 & & Modal Dynamic & Modal Dynamic & Statlc & Difference & Uplift & Downhold \\
\hline 190 & Node & Without ZPA & with $\mathrm{ZPA}$ & Dead Weight & amic-Static & Force & Force \\
\hline 191 & & Pounds & Pounds & Pounds & Pounds & Pounds & Pounds \\
\hline 192 & 5156 & 12.29 & 13.46 & 2.17 & 11.29 & 11.29 & \\
\hline 193 & 5234 & 57.13 & 285.87 & 423.60 & -137.73 & & -137.73 \\
\hline 194 & 5245 & 355.20 & 637.13 & 522.10 & 115.03 & 115.03 & \\
\hline 195 & 5339 & 19.37 & 20.63 & 2.34 & 18.30 & 18.30 & \\
\hline 196 & 5352 & 4.91 & 21.17 & 30.11 & -8.94 & & -8.94 \\
\hline 197 & 5429 & 2.63 & 4.60 & 3.65 & 0.95 & 0.95 & \\
\hline 198 & 5441 & 8.11 & 12.95 & 8.97 & 3.98 & 3.98 & \\
\hline 199 & 5514 & 2.68 & 4.61 & 3.59 & 1.03 & 1.03 & \\
\hline 200 & 5518 & 16.79 & 23.16 & 11.80 & 11.36 & 11.36 & \\
\hline 201 & 5589 & 4.68 & 6.32 & 3.04 & 3.28 & 3.28 & \\
\hline 202 & 5592 & 11.87 & 26.57 & 27.23 & -0.66 & & -0.66 \\
\hline 203 & 5666 & 0.76 & 1.71 & 1.75 & -0.05 & & -0.05 \\
\hline 204 & 5670 & 334.90 & 542.10 & 383.70 & 158.40 & 158.40 & \\
\hline 205 & 5725 & 1.13 & 2.02 & 1.65 & 0.37 & 0.37 & \\
\hline 206 & 5729 & 144.80 & 153.06 & 15.30 & 137.76 & 137.76 & \\
\hline 207 & 5771 & 0.92 & 1.82 & 1.66 & 0.16 & 0.16 & \\
\hline 208 & 5775 & 655.60 & 1022.37 & 679.20 & 343.17 & 343.17 & \\
\hline 209 & 5796 & 152.70 & 156.73 & 7.46 & 149.27 & 149.27 & \\
\hline 210 & 5819 & 1.33 & 2.66 & 2.46 & 0.19 & 0.19 & \\
\hline 211 & 5841 & 10.49 & 10.75 & 0.48 & 10.27 & 10.27 & \\
\hline 212 & 5866 & 4.19 & 5.65 & 2.71 & 2.95 & 2.95 & \\
\hline 213 & 5876 & 66.97 & 94.66 & 51.27 & 43.39 & 43.39 & \\
\hline 214 & 5912 & 6.51 & 29.62 & 42.79 & -13.17 & & -13.17 \\
\hline $2 \div 5$ & 5920 & 59.42 & 72.79 & 24.76 & 48.03 & 48.03 & \\
\hline 216 & 5933 & 22.54 & 23.64 & 2.03 & 21.61 & 21.61 & \\
\hline 217 & 5959 & 90.81 & 219.49 & 238.30 & -18.81 & & -18.81 \\
\hline 218 & 5966 & 479.20 & 605.02 & 233.00 & 372.02 & 372.02 & \\
\hline 219 & 5999 & 14.22 & 16.13 & 3.54 & 12.59 & 12.59 & \\
\hline 220 & 6009 & 41.73 & 55.69 & 25.85 & 29.84 & 29.84 & \\
\hline 221 & 6032 & 9.15 & 11.70 & 4.72 & 6.98 & 6.98 & \\
\hline 222 & 6040 & 50.31 & 54.01 & 6.86 & 47.15 & 47.15 & \\
\hline 223 & 6064 & 3.30 & 5.71 & 4.47 & 1.24 & 1.24 & \\
\hline 224 & 6067 & 1347.00 & 1760.37 & 765.50 & 994.87 & 994.87 & \\
\hline 225 & 6080 & 88.15 & 92.89 & 8.79 & 84.11 & 84.11 & \\
\hline 226 & 6092 & 0.89 & 3.45 & 4.74 & -1.29 & & -1.29 \\
\hline 227 & 6107 & 89.60 & 100.78 & 20.70 & 80.08 & 80.08 & \\
\hline 228 & 6119 & 17.77 & 19.84 & 3.83 & 16.01 & 16.01 & \\
\hline 229 & 6133 & 1975.00 & 2290.20 & 583.70 & 1706.50 & 1706.50 & \\
\hline 230 & 6148 & 38.37 & 46.48 & 15.02 & 31.46 & 31.46 & \\
\hline \multicolumn{8}{|c|}{231} \\
\hline 232 & TOTAL & 35642.44 & 47828.32 & 22565.37 & 25262.92 & 26350.54 & -1087.62 \\
\hline
\end{tabular}


영ㅇㅇㅇㅇㅇㅇㅇㅇㅇㅇㅇㅇㅇㅇㅇㅇㅇㅇㅇㅇㅇㅇㅇㅇㅇㅇㅇㅇㅇㅇㅇㅇㅇㅇㅇㅇㅇㅇㅇㅇㅇㅇ

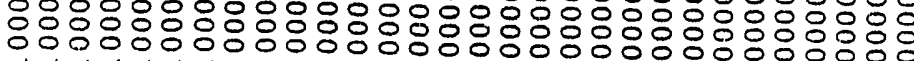

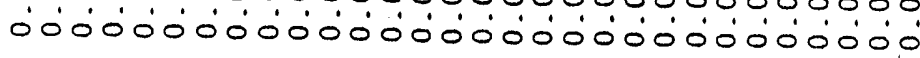

10

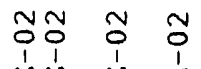

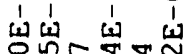

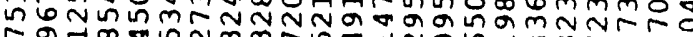
ด्र न

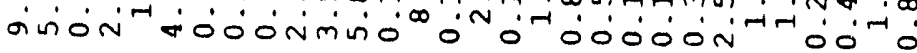

U

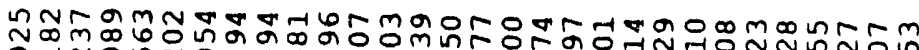

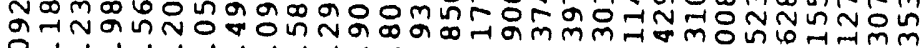

जी

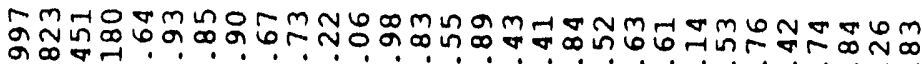
-i

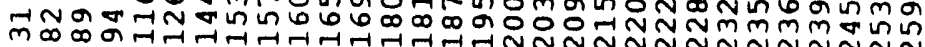

岂

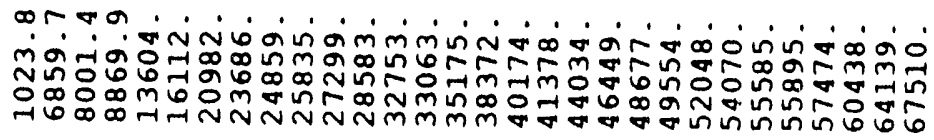

$\stackrel{\circ}{z}$

을 


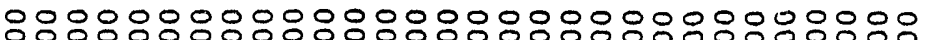

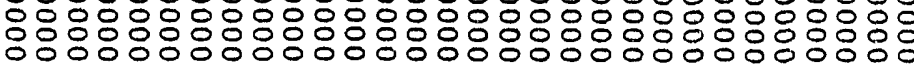

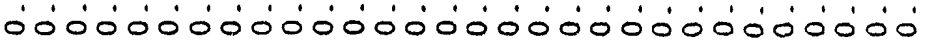

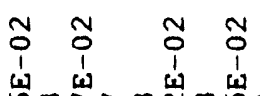

กั

矛出

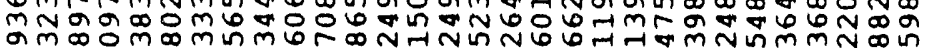

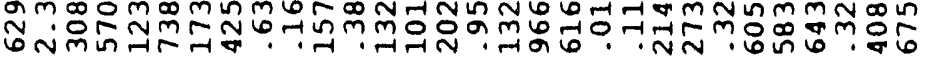
ñónom

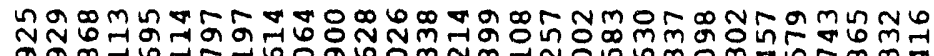
ख्न

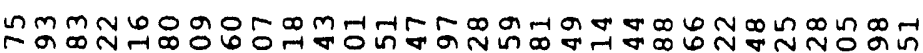

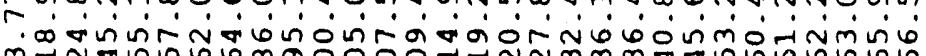

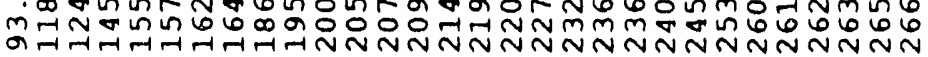

峕

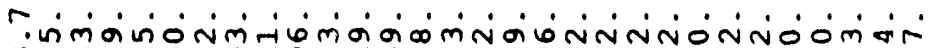
ติ 粪

은

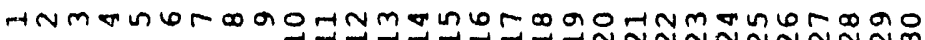

농 
-
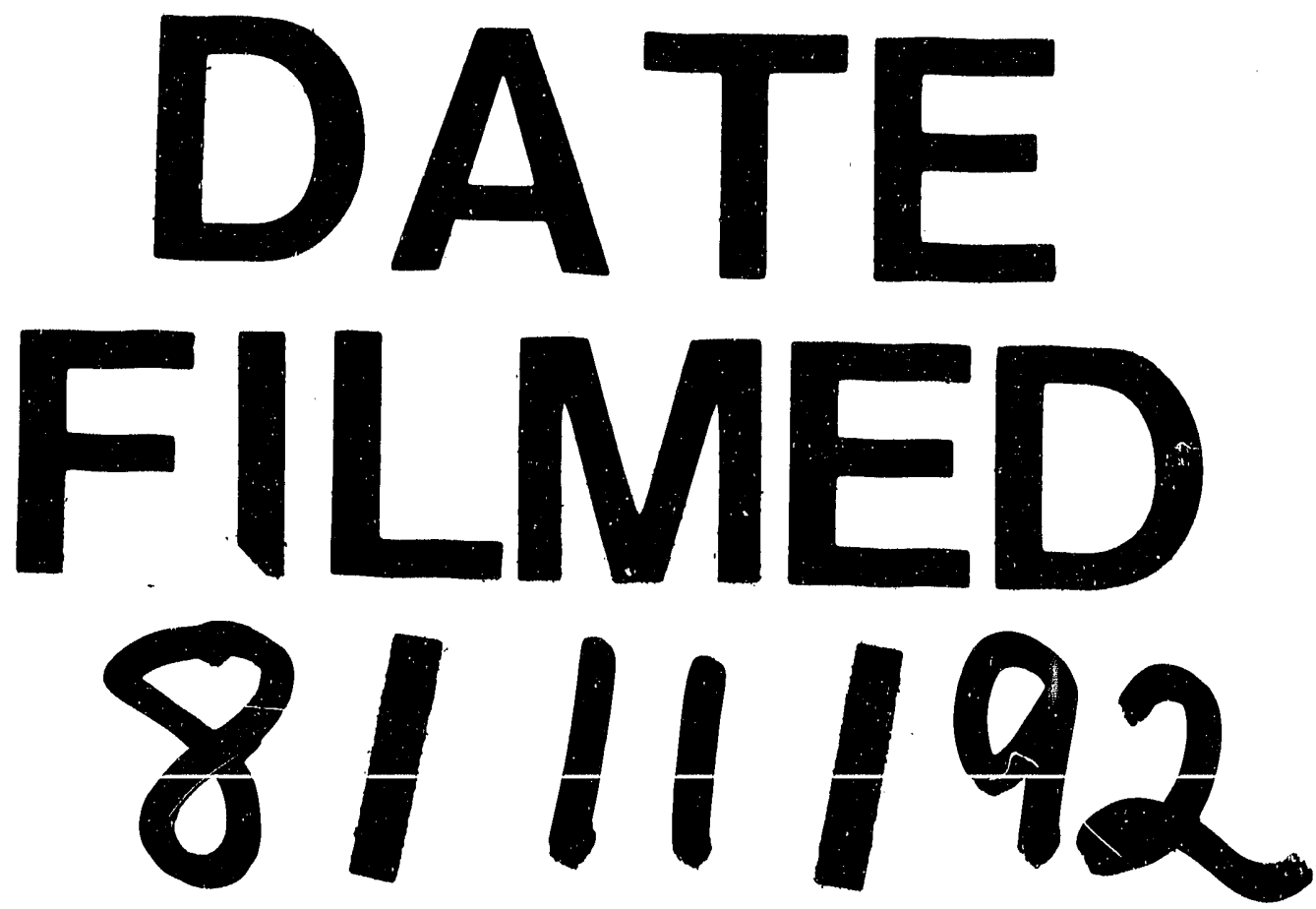
